\title{
Article
}

Subscriber access provided by Lancaster University Library

\section{A Multinuclear NMR Study of Six Forms of AIPO-34: Structure and Motional Broadening}

Daniel M. Dawson, John M Griffin, Valerie R. Seymour, Paul S. Wheatley, Mahrez Amri, Teresa Kurkiewicz, Nathalie Guillou, Stephen Wimperis, Richard I. Walton, and Sharon E. Ashbrook

J. Phys. Chem. C, Just Accepted Manuscript • DOI: 10.1021/acs.jpcc.6b11908 • Publication Date (Web): 03 Jan 2017

Downloaded from http://pubs.acs.org on January 5, 2017

\section{Just Accepted}

"Just Accepted" manuscripts have been peer-reviewed and accepted for publication. They are posted online prior to technical editing, formatting for publication and author proofing. The American Chemical Society provides "Just Accepted" as a free service to the research community to expedite the dissemination of scientific material as soon as possible after acceptance. "Just Accepted" manuscripts appear in full in PDF format accompanied by an HTML abstract. "Just Accepted" manuscripts have been fully peer reviewed, but should not be considered the official version of record. They are accessible to all readers and citable by the Digital Object Identifier (DOI®). "Just Accepted" is an optional service offered to authors. Therefore, the "Just Accepted" Web site may not include all articles that will be published in the journal. After a manuscript is technically edited and formatted, it will be removed from the "Just Accepted" Web site and published as an ASAP article. Note that technical editing may introduce minor changes to the manuscript text and/or graphics which could affect content, and all legal disclaimers and ethical guidelines that apply to the journal pertain. ACS cannot be held responsible for errors or consequences arising from the use of information contained in these "Just Accepted" manuscripts. 


\title{
A Multinuclear NMR Study of Six Forms of AlPO-34: Structure and Motional Broadening
}

\author{
Daniel M. Dawson, ${ }^{a}$ John M. Griffin, ${ }^{a, b}$ Valerie R. Seymour, ${ }^{a}$ Paul S. Wheatley, ${ }^{a}$ Mahrez \\ Amri, ${ }^{\mathrm{c}}$ Teresa Kurkiewicz, ${ }^{\mathrm{d}}$ Nathalie Guillou, ${ }^{\mathrm{e}}$ Stephen Wimperis, ${ }^{\mathrm{b}}$ Richard I. Walton ${ }^{\mathrm{c} *}$ and \\ Sharon E. Ashbrook ${ }^{\mathrm{a} *}$ \\ a School of Chemistry, EaStCHEM and Centre for Magnetic Resonance, University of St Andrews, \\ St Andrews KY16 9ST, UK \\ ${ }^{\mathrm{b}}$ Department of Chemistry, Lancaster University, Lancaster LA1 4YB, UK \\ ' Department of Chemistry, University of Warwick, Coventry CV4 7AL, UK \\ ${ }^{\mathrm{d}}$ Department of Painting Technologies and Techniques, Nicholaus Copernicus University, Torun, \\ Poland \\ ' Institut Lavoisier Versailles, UMR CNRS 8180, Université de Versailles St. Quentin, Université \\ Paris-Saclay, 78035, Versailles, France
}

* Authors to whom correspondence should be addressed Email: sema@st-andrews.ac.uk, r.i.walton@warwick.ac.uk

Submitted to J. Phys. Chem. C 


\section{Abstract}

We report a study of the CHA-type aluminophosphate AlPO-34, prepared with six different structure-directing agents (SDAs): piperidine (pip), morpholine (mor), pyridine (pyr), 1,4,8,11-tetraazacyclotetradecane (cyclam), 1,3-dimethylimidazolium (dmim) chloride and 1-ethyl-3-methylimidazolium (emim) bromide. Using a combination of solidstate NMR spectroscopy, periodic density functional theory (DFT) calculations and synchrotron X-ray diffraction, we show that, even in crystallographically well-ordered materials such as AlPO-34 with dmim as the SDA, local disorder may be present. For such disordered structures, where it is challenging to use DFT to assign NMR spectra, we show that the ${ }^{31} \mathrm{P}$ isotropic chemical shift can be predicted accurately using the mean P-O bond length and P-O-Al bond angle, in an extension of previous work. Variable-temperature ${ }^{27} \mathrm{Al}$ NMR reveals the presence of microsecond-timescale dynamics in all forms of AlPO34 , with two different motional regimes observed, depending on whether structural $\mathrm{H}_{2} \mathrm{O}$ is also present. $\mathrm{H}_{2} \mathrm{O}$ is detected in AlPO-34 prepared with mor as the SDA, although this material was previously reported as anhydrous, suggesting that this form of AlPO-34 may be hygroscopic despite the presence of the SDAs within the pores. 


\section{Introduction}

The use of small organic molecules in the crystallisation of open-framework zeolites and their analogues is well established. ${ }^{1-3}$ This stemmed from the synthesis of high-silica zeolites in the 1970s, subsequently leading to the preparation of a diverse range of phosphate-based 'zeotypes' extending from aluminophosphates (AlPOs) ${ }^{4}$ to phosphates of many elements in the Periodic Table, and other oxyanion-based solids such as germanates and sulfates..$^{5}$ Despite these considerable research efforts over decades, the role and mechanism of action of the organic species is still much debated. The name 'template' has also been used, which might imply the formation of a unique inorganic framework around the organic molecules, which can be removed to yield an open-framework structure. However, in many cases, one organic molecule may give rise to a number of different inorganic framework structures and, conversely, a particular framework may be formed using a number of different molecules. ${ }^{6}$ Furthermore, some, but not all, materials are unstable once the organic species is removed. The term 'structure-directing agent' (SDA) is, therefore, considered to be a more general way of describing the organic additives in the formation of open framework materials.

The concept of the SDA has been used to good effect in the formation of novel materials, using both organic chemistry to prepare complex, highly-specific structuredirecting molecules, ${ }^{7,8}$ and computational chemistry to 'design' such molecules to be a fit, or match, for a desired structure. ${ }^{9-11}$ However, it is still the case that the fundamental interactions between the SDA and the framework are not generally understood to such a level as to allow the choice of SDA to be made unambiguously to target the synthesis of a given framework. This is especially true for the early stages of synthesis, which take place in solution-mediated reactions, often involving amorphous precursors. ${ }^{12,13}$ The nature of interactions in the crystalline zeotype product can also be difficult to quantify by, e.g., diffraction methods, which inform only on the average structure and provide little information on motion or local disorder. In this respect, NMR spectroscopy provides an ideal local probe of the solid state ${ }^{14-16}$ and is particularly suited to the study of zeotypes that 
contain organic species, since there are several NMR-accessible probe nuclei $\left({ }^{1} \mathrm{H},{ }^{13} \mathrm{C},{ }^{15} \mathrm{~N}\right.$, ${ }^{17} \mathrm{O},{ }^{27} \mathrm{Al},{ }^{31} \mathrm{P}$, etc.) and spectra may be sensitive to local disorder ${ }^{17-21}$ and motional effects. ${ }^{22}$ This is especially powerful when used in combination with crystallographic methods.

AlPO-34 has the CHA structure type, related to the mineral chabazite, ${ }^{23}$ and the porous structure formed upon calcination has been studied for use in applications including catalysis and sorption ${ }^{24,25}$ and for its unusual thermal expansivity. ${ }^{26-28}$ AlPO-34 is of interest in the context of SDAs, as it can be prepared with a variety of organic cations, whose charge may be balanced by hydroxide or fluoride. ${ }^{23,29-34}$ Here, we use a combination of solid-state NMR spectroscopy and X-ray crystallography to investigate the arrangement of the SDAs (and any structural water present), within the pores of AlPO-34, with firstprinciples calculations used to gain insight into any positional disorder observed. During the course of our work and the preparation of this article, Xin et al. have reported AlPO-34 as a model system to examine the origin of the structure directing effect in the formation of microporous materials. ${ }^{35}$ They studied five forms of the material, with three SDAs the same as we have studied here (morpholine, piperidine and pyridine) and two other examples (diethylamine and propylamine) and used single-crystal X-ray crystallography and molecular dynamics simulations to understand SDA-framework interactions. Our work, using a combination of different experimental and theoretical approaches, is highly complementary to the work of Xin et al., since we consider local structural disorder, and we additionally study three further SDAs not considered in their work (dimethylimizadole, diethylimizadole and cyclam). However, the use of solid-state NMR spectroscopy also allows us to demonstrate experimentally the existence of microsecondtimescale dynamics within the different forms of AlPO-34, with two different motional regimes observed, depending on whether structural $\mathrm{H}_{2} \mathrm{O}$ is also present in the material. This leads to the unexpected conclusion of the presence of $\mathrm{H}_{2} \mathrm{O}$ in the morpholinecontaining material, previously suggested to be hygroscopic.

\section{Experimental methods}


Synthesis: Samples of AlPO-34 were prepared using six different organic amines or ammonium salts, viz piperidine (pip), morpholine (mor), pyridine (pyr), cyclam $(1,4,8,11$ tetraazacyclotetradecane), 1,3-dimethylimidazolium (dmim) chloride and 1-ethyl-3methylimidazolium (emim) bromide, using methods described in the literature. ${ }^{29-34}$ Full details of the syntheses are given in the Supporting Information (S1). The identity of the products was confirmed by comparison of the measured powder X-ray diffraction patterns with those simulated from crystal structures reported in the literature (where available, see Supporting Information (S2)). In the case of AlPO-34(pip), for which no crystal structure was reported at the time of our work, we measured high-resolution powder diffraction data on beamline ID31 of the European Synchrotron Radiation Facility using an X-ray wavelength of $=0.799930 \AA$ from a sample contained in a thin-walled silica capillary at room temperature. The pattern was indexed using a triclinic unit cell similar to that of AlPO-34(mor) ${ }^{33}[a=9.38191(5), b=9.16437(5), c=9.19177(7) \AA, \alpha=87.7602(6), \beta=$ 102.0428(7), $\left.\gamma=93.4886(6)^{\circ}\right]$. That led to the conclusion that the two compounds are isostructural and, thus, the atomic coordinates of AlPO-34(mor) were then directly used as starting model in the Rietveld refinement. The Supporting Information describes the numbering scheme for the framework oxygen atoms (S3) and full detail of the structure refinement of AlPO-34(pip) and shows the final Rietveld plot and crystal data (S4).

Analysis: Simultaneous thermogravimetric analysis (TGA), differential scanning calorimetry (DSC) and mass spectrometry (MS) were performed using a Mettler Toledo TGA/DSC 1-600 instrument with a Hiden HPR-20 QIC R\&D specialist gas analysis system, a triple filter mass spectrometer with SEM detection. Approximately $10 \mathrm{mg}$ of each powder was loaded into separate alumina crucibles and data recorded on heating in air to $800{ }^{\circ} \mathrm{C}$ at $10{ }^{\circ} \mathrm{C} \mathrm{min}^{-1}$. Further details are given in the Supporting Information (S5).

Solid-state NMR: Solid-state NMR spectra were recorded on Bruker Avance III spectrometers equipped with either a $9.4 \mathrm{~T}$ or $14.1 \mathrm{~T}$ wide-bore superconducting magnet. For ${ }^{1} \mathrm{H}$ NMR spectra, samples were packed into $1.3 \mathrm{~mm}$ zirconia rotors and rotated at the magic angle at $55 \mathrm{kHz}$. Spectra were recorded using a rotor-synchronised spin-echo pulse 
sequence (echo interval $=18.2 \mu \mathrm{s}$ ) to reduce background signal, with signal averaging for 128 transients with a repeat interval of $3 \mathrm{~s}$. For ${ }^{13} \mathrm{C}$ NMR spectra, samples were packed into $4 \mathrm{~mm}$ zirconia rotors and rotated at the magic angle at $12.5 \mathrm{kHz}$. Spectra were recorded using cross polarisation (CP) from ${ }^{1} \mathrm{H}$ with a spin lock pulse (ramped for ${ }^{1} \mathrm{H}$ ) of between 0.5 and $2.5 \mathrm{~ms}$. TPPM-15 decoupling of ${ }^{1} \mathrm{H}\left(\mathrm{v}_{1}=100 \mathrm{kHz}\right)$ was applied during acquisition. Signal averaging was carried out for between 456 and 19240 transients with a repeat interval of 3 to $10 \mathrm{~s}$. For ${ }^{15} \mathrm{~N}$ CP MAS NMR spectra, samples were packed into $4 \mathrm{~mm}$ zirconia rotors and rotated at the magic angle at $5 \mathrm{kHz}$ (where the slow MAS rate was used to enhance the relatively weak ${ }^{1} \mathrm{H}^{15} \mathrm{~N}$ dipolar coupling used to transfer magnetisation in the $\mathrm{CP}$ experiment). Spectra were recorded using $\mathrm{CP}$ from ${ }^{1} \mathrm{H}$ with a spin lock pulse (ramped for $\left.{ }^{1} \mathrm{H}\right)$ of between 1 and $10 \mathrm{~ms}$. TPPM-15 decoupling of ${ }^{1} \mathrm{H}\left(v_{1}=100\right.$ $\mathrm{kHz}$ ) was applied during acquisition. Signal averaging was carried out for between 13736 and 65568 transients with a repeat interval of 5 s. For ${ }^{19} \mathrm{~F}$ NMR spectra, samples were packed into $1.3 \mathrm{~mm}$ zirconia rotors and rotated at the magic angle at $55 \mathrm{kHz}$. Spectra were recorded using a rotor-synchronised spin-echo pulse sequence (echo interval $=18.2 \mu \mathrm{s}$ ) to reduce background signal, with signal averaging for between 32 and 128 transients with a repeat interval of 5 or $10 \mathrm{~s}$. For ${ }^{31} \mathrm{P}$ NMR spectra, samples were packed into $4 \mathrm{~mm}$ zirconia rotors and rotated at the magic angle at $12.5 \mathrm{kHz}$. Spectra were recorded with signal averaging for 16 transients with a repeat interval of $60 \mathrm{~s}$. For ${ }^{27} \mathrm{Al}$ NMR spectra, samples were packed into $4 \mathrm{~mm}$ zirconia rotors and rotated at the magic angle at $12.5 \mathrm{kHz}$. MAS spectra were recorded with signal averaging for 64 transients with a repeat interval of $3 \mathrm{~s}$. The ${ }^{27} \mathrm{Al}$ MQMAS spectra were recorded using a split- $\mathrm{t}_{1}$ shifted-echo pulse sequence with signal averaging for 96-192 transients for each of 64-144 $t_{1}$ increments of $103.35 \mu \mathrm{s}$. The spectra were referenced in the indirect dimension according to Ref. 36. For hightemperature experiments, the sample temperature was maintained using a Bruker BCU-II chiller and Bruker BVT/BVTB-3000 temperature controller and heater booster. The sample temperature (including frictional heating effects arising from sample spinning) was calibrated using the isotropic ${ }^{87} \mathrm{Rb}$ shift of solid $\mathrm{RbCl} .{ }^{37}$ For the ${ }^{27} \mathrm{Al}$ variable-temperature spectra, the magic angle was accurately calibrated at each temperature using the ${ }^{87} \mathrm{Rb}$ satellite transitions of $\mathrm{RbNO}_{3}$ or $\mathrm{Rb}_{2} \mathrm{SO}_{4}$. Chemical shifts are reported relative to TMS $\left({ }^{1} \mathrm{H}\right.$ 
and $\left.{ }^{13} \mathrm{C}\right), \mathrm{CH}_{3} \mathrm{NO}_{2}\left({ }^{15} \mathrm{~N}\right), \mathrm{CFCl}_{3}\left({ }^{19} \mathrm{~F}\right), 1.1 \mathrm{M} \mathrm{Al}\left(\mathrm{NO}_{3}\right)_{3}$ in $\mathrm{D}_{2} \mathrm{O}\left({ }^{27} \mathrm{Al}\right)$ and $85 \% \mathrm{H} 3 \mathrm{PO} 4\left({ }^{31} \mathrm{P}\right)$ using secondary solid references of L-alanine $\left(\mathrm{NH}_{3}=8.5 \mathrm{ppm}, \mathrm{CH}_{3}=20.5 \mathrm{ppm}\right)$, glycine $\left(\mathrm{NH}_{3}=-\right.$ $347.4 \mathrm{ppm}), \operatorname{PTFE}\left(\mathrm{CF}_{2}=-122.7 \mathrm{ppm}\right), \mathrm{Al}(\mathrm{acac})_{3}\left(\delta_{\text {iso }}=0.0 \mathrm{ppm}, \mathrm{C}_{\mathrm{Q}}=3.0 \mathrm{MHz}, \eta_{\mathrm{Q}}=0.15\right)$ and $\mathrm{BPO}_{4}(-29.6 \mathrm{ppm})$.

Calculations: Geometry optimisations and calculation of NMR parameters were carried out using the CASTEP density functional theory (DFT) code (version 6), ${ }^{38}$ employing the GIPAW algorithm, ${ }^{39}$ to reconstruct the all-electron wavefunction in the presence of a magnetic field. The initial structures were taken from the literature or XRD, and models constructed based on information provided in the literature or from the XRD refinements. Calculations were performed using the GGA PBE functional, with core-valence interactions described by ultrasoft pseudopotentials. ${ }^{40}$ A planewave energy cut off of 50 Ry was used, and integrals over the Brillouin zone were performed using a Monkhurst-Pack grid with k-point spacing of $0.042 \pi \AA^{-1}$. Dispersive interactions were reintroduced using the scheme of Grimme, ${ }^{41}$ as implemented by McNellis et al. ${ }^{42}$ Calculations were performed on a 198-node (2376 core) Intel Westmere cluster with 2 GB memory per core and QDR Infiniband interconnect at the University of St Andrews.

The isotropic shielding is given by, $\sigma_{\text {iso }}=(1 / 3) \operatorname{Tr}\{\sigma\}$, and the isotropic chemical shift, $\delta_{\text {iso }}$ by $-\left(\sigma_{\text {iso }}-\sigma_{\text {ref }}\right)$, where $\sigma_{\text {ref }}$ is a reference shielding. Further details on the referencing are provided in the Supporting Information (S6). The magnitude of the quadrupolar coupling constant is given by $\mathrm{C}_{\mathrm{Q}}=\mathrm{eQV}_{\mathrm{zz}} / \mathrm{h}$, where $\mathrm{Q}$ is the nuclear quadrupole moment (for which a value of $146.6 \mathrm{mb}$ was used for ${ }^{27} \mathrm{Al}$ ). ${ }^{43}$ The asymmetry parameter is given by $\eta_{\mathrm{Q}}=\left(\mathrm{V}_{\mathrm{XX}}-\mathrm{V}_{\mathrm{YY}}\right) / \mathrm{V}_{\mathrm{ZZ}}$.

\section{Results and Discussion}

The Crystal Structures of As-Made AlPO-34 
Figure 1(a) shows the structures of the six SDAs used in this study: 1,3dimethylimidazolium (dmim) ${ }^{29,30}$ 1-ethyl,3-methyl-imidazolium (emim) ${ }^{29,30}$ pyridine $($ pyr $){ }^{31}$ piperidine (pip), ${ }^{32}$ morpholine (mor), ${ }^{33}$ and 1,4,8,11-tetraazacyclotetradecane (cyclam). ${ }^{34}$ The six AlPOs prepared with these SDAs are hereafter denoted AlPO-34(SDA). The crystal structures of five of these AlPOs had previously been reported..$^{29-31,33,34}$ However, although AlPO-34(pip) has been prepared several times before, ${ }^{32,44,45}$ its structure was only reported very recently, during the preparation of this manuscript. ${ }^{35}$ At the time of our work the structure was unknown, and so high-resolution powder synchrotron X-ray diffraction measurements were undertaken in order to determine a crystal structure for this form of as-made AlPO-34. Selected crystallographic parameters for AlPO-34(pip) are summarized in Table 1 and, as described in the Supporting Information (S4), two possible structures of AlPO-34(pip) could be refined equally well against the diffraction data: one model with a single configuration for the pip cations (AlPO-34(pip-1)) and one with the $\mathrm{N}$ atom of the pip disordered over the 1 and 3 positions of the ring (AlPO-34(pip-2)). Regardless of the SDA orientation, a partially-occupied $\mathrm{H}_{2} \mathrm{O}$ site was located in Fourier difference maps during structure solution that corresponds to $0.4 \mathrm{H}_{2} \mathrm{O}$ per $3 \mathrm{Al}$ (i.e., $40 \%$ occupancy). The presence of a partially-occupied molecule of $\mathrm{H}_{2} \mathrm{O}$ is consistent with the published structure of AlPO-34(pyr), ${ }^{31}$ which contains a 15\% occupied molecule of water in a similar position within the unit cell. Each of the possible structures determined for AlPO-34(pip) differs from that of Xin et al., which was refined with 25\% occupancy of the $\mathrm{H}_{2} \mathrm{O}$ and only one orientation of the pip. ${ }^{35}$ Furthermore, the orientations of the SDA are different for our refined structures and that of Xin et al. (see the Supporting Information (S4) for further discussion of these differences). It should be noted that, in the DFT calculations discussed in detail in the Supporting Information (S6), for both the dehydrated and hydrated forms of AlPO-34(pip), both of the structural models determined here are $\sim 0.7-0.8 \mathrm{eV}$ more stable than that proposed by Xin et al.

The as-made AlPO-34 materials studied here all crystallise with an anionic framework of empirical composition $\left[\mathrm{Al}_{3} \mathrm{P}_{3} \mathrm{O}_{12} \mathrm{~F}\right]^{-}$. This also represents the inorganic part of the asymmetric unit: there are three crystallographically-unique $\mathrm{P}$ and $\mathrm{Al}$ sites, each 
connected by four Al-O-P linkages, giving three $\mathrm{PO}_{4}$ and two $\mathrm{AlO}_{4}$ tetrahedra, as shown in Figure 1(b). The remaining $\mathrm{Al}$ (Al1 in our numbering scheme) has an octahedral $\mathrm{AlO}_{4} \mathrm{~F}_{2}$ environment, where bridging fluorides form Al-F-Al linkages between neighbouring pairs of Al1. It should be noted that the numbering schemes used in the original literature for Al and $\mathrm{P}$ in the various forms of AlPO-34 are different. Here, we will use the consistent numbering scheme shown in Figure 1(b) to enable direct comparison of framework species in the different forms of AlPO-34. The Supporting Information (S3) contains a more detailed description of this numbering scheme, including the numbering of the framework $\mathrm{O}$ species. As with almost all three-dimensional AlPOs, the $\mathrm{AlO}_{4}$ and $\mathrm{PO}_{4}$ tetrahedra in AlPO-34 are in strict alternation, giving an overall neutral $\mathrm{AlPO}_{4}$ framework, with the charge of the Al-bound fluoride anions balanced by that of the cationic SDAs, which reside in the $\mathrm{CHA}$ cages.

The presence of $\mathrm{H}_{2} \mathrm{O}$ in two of the hydrothermally-prepared samples is perhaps not surprising, although the presence of water was not determined previously by diffraction in either AlPO-34(mor) ${ }^{33}$ or AlPO-34(cyclam), ${ }^{34}$ which are also prepared in aqueous media. AlPO-34(dmim) and AlPO-34(emim) are synthesised ionothermally, with a very low volume of $\mathrm{H}_{2} \mathrm{O}$ present and no $\mathrm{H}_{2} \mathrm{O}$ was located in their structures. ${ }^{29,30}$ Most of the crystal structures for as-made AlPO-34 indicate that the SDAs may be conformationally disordered. AlPO-34(dmim) was refined by Morris and coworkers ${ }^{29,30}$ as fully ordered, but the analogous AlPO-34(emim) displays six-fold conformational disorder of the alkyl chains (two possible arrangements of $\mathrm{CH}_{3}$ and $\mathrm{C}_{2} \mathrm{H}_{5}$, with three-fold disorder of each $\mathrm{C}_{2} \mathrm{H}_{5}$ ). As described in the Supporting Information (S4), one of the two possible structural models obtained for AlPO-34(pip), AlPO-34(pip-2), contains two orientations of the SDA. Therefore, it is perhaps surprising that the structurally very similar morpholinium was refined in a single orientation, ${ }^{33}$ as was pyridinium, ${ }^{31}$ both of which have the potential for disorder of the heteroatom location(s). Wheatley and Morris observed that, in addition to expected disorder of the protonated and neutral $\mathrm{N}$ species of cyclam (owing to the presence of four $\mathrm{N}$ atoms and only two $\mathrm{H}^{+}$), the entire SDA could be refined as occupying two orientations within the pores of AlPO-34(cyclam). ${ }^{34}$ In order to investigate the 
presence of any non-periodic disorder of the SDA and potentially partially-occupied water species, all materials were characterised here by ${ }^{1} \mathrm{H},{ }^{13} \mathrm{C},{ }^{15} \mathrm{~N},{ }^{19} \mathrm{~F},{ }^{27} \mathrm{Al}$ and ${ }^{31} \mathrm{P} \mathrm{NMR}$ spectroscopy with the experimental results compared to periodic DFT calculations to aid assignment and interpretation.

\section{DFT Calculations}

Periodic DFT calculations are now well established as a useful tool for assigning the NMR spectra of solids, as well as evaluating potential structural models where some uncertainty exists over the true structure. ${ }^{11,17-19,46-49}$ As most of the forms of as-made AlPO-34 considered here have crystal structures refined with disorder of the SDA (emim and cyclam), ${ }^{29,30,34}$ water (pyr) ${ }^{31}$ or both (pip), ${ }^{32}$ DFT calculations were used to help interpret and assign the experimental NMR spectra. One crucial requirement for the prediction of accurate NMR parameters from a given structure is that the structure itself must represent a realistic minimum on the energy landscape. ${ }^{17,47,49,50}$ In order to ensure this is the case, the atomic coordinates and, often, unit cell parameters can (or, indeed, must) be optimised to an energy minimum. Sneddon et al..$^{50}$ recently investigated the computational parameters most suited to the optimisation of AlPOs and showed that the optimisation of all atomic coordinates and unit cell parameters with the inclusion of semi-empirical dispersion correction schemes yielded results in good agreement with both crystallographic and spectroscopic measurements, without applying any a priori constraints to the structural model. For details of the exact structural models considered and computational methods used, see the Experimental Details and Supporting Information (S6). The results of these calculations are described in depth in the Supporting Information (S6 and S7) and the calculated NMR parameters are discussed and compared with the experimental results below.

Solid-State NMR Spectroscopy 
The ${ }^{1} \mathrm{H}$ MAS NMR spectra of the six as-made AlPO-34 materials are shown in Figure 2. The spectrum of AlPO-34(dmim) contains resonances at 12.6, 7.8, 4.1 and between 0.8 and $2.0 \mathrm{ppm}$. The resonances at 7.8 and $4.1 \mathrm{ppm}$ with higher intensity can be assigned to $\mathrm{H} 2+$ $\mathrm{H} 3$ and H4, respectively, whereas the other two resonances (which have much lower intensity) cannot be assigned to the dmim. However, as the dmim originates from transalkylation of the 1-ethyl,3-methylimidazolium chloride ionic liquid used in the synthesis, $^{51}$ the resonances between 0.8 and $2.0 \mathrm{ppm}$ can be assigned to $\mathrm{H} 7$ of emim present within the pores instead of dmim (in analogy with AlPO-34(emim), discussed below). DFT calculations discussed in the Supporting Information (S6 and S7), indicate that the resonance at $12.6 \mathrm{ppm}$ may arise from 1-alkylimidazolium (calculated NH shift of 9-11 ppm), resulting from hydrolysis, rather than transalkylation, of the ionic liquid. Owing to the greater degree of disorder of the orientation of the SDA in AlPO-34(emim), the ${ }^{1} \mathrm{H}$ NMR spectrum of this material is of lower resolution than that of the more ordered AlPO-34(dmim). Groups of resonances are observed at 1.0-2.1, 3.5-4.7 and 6.7-9.2 ppm and can be generally assigned to $\mathrm{H} 7, \mathrm{H} 6+\mathrm{H} 8$ and $\mathrm{H} 2+\mathrm{H} 4+\mathrm{H} 5$, respectively. Again, a resonance at $13.1 \mathrm{ppm}$ can be attributed to 1-alkylimidazolium species, in analogy to AlPO-34(dmim). The ${ }^{1} \mathrm{H}$ NMR spectrum of AlPO-34(pyr) is well resolved, with distinct resonances observed at 15.2, 8.6, 8.1, 3.0 and $1.1 \mathrm{ppm}$. These resonances can be assigned to H1 (15.2 ppm), H2 + H4 (8.6 ppm) and H3 (8.1 ppm) of the SDA by analogy with the pyrcontaining CHA-type gallophosphate, GaPO-34. ${ }^{52}$ The resonance at 3.0 ppm confirms the presence of $\mathrm{H}_{2} \mathrm{O}$. However, the resonance at $1.1 \mathrm{ppm}$ may be attributed to $\mathrm{CH}_{3}$ in traces of triethylamine, which was also present in the synthesis $\left(\sim 1: 0.12\right.$ mole ratio of pyr $: \mathrm{Et}_{3} \mathrm{~N}$, according to the integrated intensities of the resonances at 15.2 and $1.1 \mathrm{ppm})$. The $\mathrm{N}-\mathrm{CH}_{2}$ resonance of $\mathrm{Et}_{3} \mathrm{~N}$ would also be expected to have a shift of $\sim 3 \mathrm{ppm}$, and may, therefore, overlap with any signal from $\mathrm{H}_{2} \mathrm{O}$. Accounting for the $\mathrm{Et}_{3} \mathrm{~N}$, the integrated intensities (including spinning sidebands) of the ${ }^{1} \mathrm{H}$ NMR spectrum indicate $\sim 0.15 \mathrm{H}_{2} \mathrm{O}$ per $3 \mathrm{Al}$ (in agreement with Ref. 31). The ${ }^{1} \mathrm{H}$ NMR spectrum of AlPO-34(pip) has resonances at 9.1, 6.6, 3.4 and $2.0 \mathrm{ppm}$, corresponding to $\mathrm{H} 1$ hydrogen bonded to $\mathrm{H}_{2} \mathrm{O}$, non-hydrogen-bonded $\mathrm{H} 1, \mathrm{H} 2+\mathbf{H}_{2} \mathrm{O}$ and $\mathrm{H} 3+4$, respectively. Integration of the spectrum using DMFit ${ }^{53}$ (discussed in the Supporting Information (S7)) reveals a stoichiometry of $\sim 0.5 \mathrm{H}_{2} \mathrm{O}$ per $3 \mathrm{Al}$ 
(i.e., higher than the value determined by the crystallographic measurements described above). The ${ }^{1} \mathrm{H}$ NMR spectrum of AlPO-34(mor) is poorly resolved, containing two broad resonances from 1-6 and 6-9 ppm, which can be assigned, respectively, to H2 + H3 and H4. It should be noted that the low resolution of the spectrum indicates a greater degree of disorder than might be expected from a material whose single-crystal structure was refined with no SDA disorder or partially-occupied water..$^{33}$ It is, therefore, possible that the mor exhibits greater conformational or orientational flexibility than indicated in the published structures, both of which contain a single cation conformation. ${ }^{33,35}$ Another possibility, as will be discussed in more detail below, is that water is also included in the structure depending on either the synthesis route or the conditions under which the sample is studied. The ${ }^{1} \mathrm{H}$ NMR spectrum of AlPO-34(cyclam) is of very low resolution, even at a MAS frequency of $55 \mathrm{kHz}$. This lack of resolution is likely to be a consequence of the significant cation disorder observed in the published crystal structure (determined from single-crystal synchrotron X-ray diffraction). ${ }^{34}$ In addition to the conformational and orientational flexibility observed in the earlier crystallographic study, there is also likely to be disorder of the two $\mathrm{H}^{+}$attached to the four chemically-equivalent $\mathrm{N}$ species.

The ${ }^{13} \mathrm{C}$ CP MAS NMR spectra of the six samples of AlPO-34 are also shown in Figure 2. The ${ }^{13} \mathrm{C}$ NMR spectra of both AlPO-34(dmim) and AlPO-34(emim) were previously reported by Griffin et al.,$^{51}$ although no detailed assignment was made. For AlPO-34(dmim), although the two $\mathrm{CH}_{3}$ groups of the SDA are chemically equivalent, the presence of the AlPO framework surrounding the SDA leads to a crystallographic inequivalence of these two groups, giving rise to two sharp ${ }^{13} \mathrm{C}$ resonances at 36.6 and 37.5 ppm. In addition, two resonances are observed at 125.0 and $126.0 \mathrm{ppm}$, corresponding to the crystallographically-distinct $\mathrm{C} 3$, and one resonance at $134.3 \mathrm{ppm}$, corresponding to $\mathrm{C} 2$ (see the Supporting Information (S6 and S7) for further details). It should be noted that ${ }^{13} \mathrm{C}$ NMR spectroscopy is predicted to be relatively insensitive to the presence of 1methylimidazoium within the pores of AlPO-34(dmim), as all calculated chemical shifts for this molecule are very similar to those of dmim. The presence of disordered methyl and ethyl groups in AlPO-34(emim) leads to a much more complicated spectrum than for 
AlPO-34(dmim). C7 gives rise to a broad resonance between 11.5 and $20 \mathrm{ppm}, \mathrm{C} 8$ to a broadened resonance between 36 and 39 ppm (consistent with the shifts observed for AlPO-34(dmim)) and C6 to two sharp resonances at 46.2 and $49.2 \mathrm{ppm}$ and a broader feature between 43 and $45 \mathrm{ppm}$. The presence of disorder is also evident from the aromatic species, C2, C4 and C5, which give rise to more than 10 discernible resonances between 119 and 148 ppm, the assignment of which is discussed in greater detail in the Supporting Information (S6 and S7). The ${ }^{13} \mathrm{C}$ NMR spectrum of AlPO-34(pyr) contains three resonances at 128.6, 141.2 and $147.8 \mathrm{ppm}$, corresponding to C3, C2 and C4, respectively (cf. the assignment for the GaPO- $34^{52}$ analogue). As observed by ${ }^{1} \mathrm{H}$ NMR, there appears to be some triethylamine present in the material, giving rise to two minor resonances at 11 and $49 \mathrm{ppm}$ in the ${ }^{13} \mathrm{C}$ NMR spectrum. It is interesting to note that, although the resolution of the ${ }^{1} \mathrm{H}$ NMR spectrum of this sample (discussed above) indicated that the material is relatively ordered, the presence of the fractionally-occupied $\mathrm{H}_{2} \mathrm{O}$ appears to lead to a distribution of local environments that affect the ${ }^{13} \mathrm{C}$ isotropic shifts, giving rise to linewidths between 250 and $400 \mathrm{~Hz}$. The ${ }^{13} \mathrm{C}$ NMR spectrum of AlPO-34(pip) contains two resonances at 22.9 and $47.5 \mathrm{ppm}$, corresponding to $\mathrm{C} 3+\mathrm{C} 4$ and $\mathrm{C} 2$, respectively. While no evidence is observed for the two-site disorder (present in the AlPO-34(pip-2) structure refined for this work), the linewidths of $\sim 240 \mathrm{~Hz}$ are perhaps indicative of the presence of some disorder - consistent with the conclusions from the ${ }^{1} \mathrm{H}$ NMR spectrum (see above). Furthermore, as discussed in the Supporting Information (S7), it is difficult to distinguish between the two possible structures using the DFT-calculated ${ }^{13} \mathrm{C}$ NMR parameters. AlPO34 (mor) gives rise to two ${ }^{13} \mathrm{C}$ resonances at 46.0 and $65.1 \mathrm{ppm}$, corresponding to $\mathrm{C} 3$ and $\mathrm{C} 2$, respectively. As for AlPO-34(pip), the linewidths of $\sim 400 \mathrm{~Hz}$ are consistent with the presence of disorder, as observed in the ${ }^{1} \mathrm{H}$ NMR spectrum. The disorder of the SDA in AlPO-34(cyclam) gives rise to complicated ${ }^{13} \mathrm{C}$ lineshapes, with three distinct resonances at 22.0, 24.7 and 27.4 ppm corresponding to $\mathrm{C} 6$ and at least nine distinct resonances between 38 and 51 ppm corresponding to $\mathrm{C} 2+\mathrm{C} 3+\mathrm{C} 5+\mathrm{C} 7$.

The low natural abundance $(0.368 \%)$ and gyromagnetic ratio $\left(\gamma_{15 \mathrm{~N}} / \gamma_{1 \mathrm{H}}=0.101\right)$ of ${ }^{15} \mathrm{~N}$ makes study of this nucleus time consuming (at natural abundance). However, its larger 
chemical shift range ( $900 \mathrm{ppm})$ compared to ${ }^{13} \mathrm{C}(\sim 250 \mathrm{ppm})$ means that ${ }^{15} \mathrm{~N}$ should be more sensitive to small differences in the local environment of the SDA, arising from, e.g., disorder. The ${ }^{15} \mathrm{~N}$ CP MAS NMR spectra of the six forms of AlPO-34 are shown in Figure 2. As was observed for ${ }^{13} \mathrm{C}$, the symmetry of the dmim is broken by the AlPO framework, giving rise to two resonances at -205.8 and -212.7 ppm in the ${ }^{15} \mathrm{~N}$ NMR spectrum of AlPO34(dmim). The disorder in AlPO-34(emim) leads to a more complicated ${ }^{15} \mathrm{~N}$ NMR spectrum, with resonances at $-177.9,-179.3,-194.9$ and $-197.6 \mathrm{ppm}$, as well as between 204 and -213 ppm. The shifts of these latter resonances are similar to those observed for AlPO-34(dmim), suggesting their assignment as N3, meaning that the resonances at higher chemical shift can, therefore, tentatively be assigned to N1. As might be expected, the ${ }^{15} \mathrm{~N}$ NMR spectra of AlPO-34(pyr), AlPO-34(pip) and AlPO-34(mor) each contain a single resonance, at $-179,-337$ and -341 ppm, respectively. However, these resonances are considerably broader ( 100, 110 and $\sim 240 \mathrm{~Hz}$, respectively) than that of AlPO-34(dmim) $(\sim 35 \mathrm{~Hz})$, again suggesting that there may be disorder present in all three materials and precluding any definite determination of whether AlPO-34(pip) contains ordered or disordered piperidinium cations (as discussed in the Supporting Information (S7), the ${ }^{15} \mathrm{~N}$ resonances in the disordered AlPO-34(pip-2) would be expected to have a shift difference of $\sim 1$ ppm $(40.6 \mathrm{~Hz}))$. The ${ }^{15} \mathrm{~N}$ NMR spectrum of AlPO-34(cyclam) contains numerous resonances between -358 and $-330 \mathrm{ppm}$. In agreement with the ${ }^{1} \mathrm{H}$ and ${ }^{13} \mathrm{C}$ spectra, the ${ }^{15} \mathrm{~N}$ NMR spectrum of AlPO-34(cyclam) indicates the presence of significant disorder (i.e., suggesting that more than the two conformations of cyclam proposed in the original structure of Wheatley and Morris ${ }^{34}$ may be present).

The ${ }^{19} \mathrm{~F}$ MAS NMR spectra of all six samples, shown in Figure 3, confirm the presence of bridging fluoride. Single resonances are observed in the spectra of AlPO34(dmim), AlPO-34(pyr) and AlPO-34(pip), with isotropic shifts of $-124.9,-128.2$ and 125.7 ppm, respectively. However, a small shoulder at $-123.1 \mathrm{ppm}$ in the spectrum of AlPO-34(dmim) can be observed ( $3 \%$ of the spectral intensity) and may be attributed to the presence of small amounts of 1-methylimidazolium impurities, forming an $\mathrm{N}-\mathrm{H}^{\cdots} \mathrm{F}$ hydrogen bond (see the Supporting Information (S6 and S7) for details), in agreement with 
the ${ }^{1} \mathrm{H}$ NMR spectrum discussed above. The ${ }^{19} \mathrm{~F}$ NMR spectrum of AlPO-34(mor) can be decomposed into two resonances with isotropic shifts of -126.7 and $-128.2 \mathrm{ppm}$, with an integrated intensity ratio of about 2 : 1. For AlPO-34(cyclam), two well-resolved resonances are observed at -126.3 and $-129.9 \mathrm{ppm}$ in a $3: 1$ integrated intensity ratio. As shown in the Supporting Information (S8), a ${ }^{19} \mathrm{~F}$ double-quantum correlation spectrum suggests that both resonances arise from the same chemical phase, which indicates considerable structural variation in the local environment of $\mathrm{F}$ in this material. However, the DFT calculations were unable to provide further insight into the assignment of these two resonances. For AlPO-34(emim), a broad resonance is observed between -122.0 and 127.8 ppm, and the lineshape appears to have multiple overlapping components, indicative of a disordered material. The differences in ${ }^{19} \mathrm{~F}$ chemical shifts suggest slight differences in Al-F bond lengths and the proximity of the SDA (and $\mathrm{H}_{2} \mathrm{O}$, if present).

The ${ }^{31} \mathrm{P}$ MAS NMR spectra of the six samples of AlPO-34 are shown in Figure 3 and, in each case, three resonances are observed, corresponding to the three crystallographically-distinct $\mathrm{P}$ sites (or the three sets of pseudo-equivalent $\mathrm{P}$ sites, where local disorder leads to more than three formally distinct P). Assignment of the P sites can be made based on the relationship between ${ }^{31} \mathrm{P}$ chemical shift and the mean $\mathrm{P}-\mathrm{O}-\mathrm{Al}$ bond angle, $\left\langle\theta_{\mathrm{POA}}\right\rangle$, and the mean $\mathrm{P}-\mathrm{O}$ bond length, $\left\langle\mathrm{r}_{\mathrm{PO}}\right\rangle$, determined using computation by Dawson and Ashbrook, ${ }^{54}$ in an extension to much earlier work. While this relationship was only demonstrated for calcined AlPOs in the original work, further investigation shows, perhaps surprisingly, that a similar relationship holds for as-made AlPOs. In the AlPOs studied here, one of the dominant structural features influencing $\delta_{\text {iso }}$ is the small $(\sim 125-$ $\left.130^{\circ}\right) \mathrm{P}-\mathrm{O}-\mathrm{Al}$ bond angles arising from the distortion of the framework by the Al-bound fluoride. Figure $4(\mathrm{a})$ plots $\left\langle\theta_{\mathrm{POAl}}\right\rangle$ against $\left\langle\mathrm{r}_{\mathrm{PO}}\right\rangle$ for the three inequivalent $\mathrm{P}$ species in each of the eight experimental crystal structures of as-made AlPO-34. The ranges of $\left\langle\mathrm{r}_{\mathrm{PO}}\right\rangle$ for the three $\mathrm{P}$ species are significantly overlapped, whereas the ranges of $\left\langle\theta_{\mathrm{POAl}}\right\rangle$ are well separated. Therefore, it can be assumed that, for the as-made AlPO-34, to a first approximation, variations in $\left\langle\theta_{\mathrm{POAl}}\right\rangle$ will dominate the value of $\delta_{\text {iso }}$ observed. Figure $4(\mathrm{~b})$ plots the experimentally-determined $\left\langle\theta_{\text {POAl }}\right\rangle$ against ${ }^{31} \mathrm{P} \delta_{\text {iso }}$ for the six as-made forms of 
AlPO-34 studied here and it can be seen that there is a general trend of increasing $\delta_{\text {iso }}$ with decreasing $\left\langle\theta_{\mathrm{POA}}\right\rangle$. The line of best fit for all eight structures has the equation

$$
\delta_{\text {iso }}=-1.209\left\langle\theta_{\mathrm{POAl}}\right\rangle+149.1
$$

Equation 1 can be compared to the relationships between ${ }^{31} \mathrm{P} \delta_{\text {iso }}$ and $\left\langle\theta_{\mathrm{POAl}}\right\rangle$ reported by Müller et al. ${ }^{55}$ and Kanehashi et al.., ${ }^{56}$ with the gradient observed here closer to that of the latter study (-1.25 ppm per degree) than the former (-0.52 ppm per degree). As discussed in the Supporting Information (S9), a relationship dependent on both $\left\langle\theta_{\mathrm{POAl}}\right\rangle$ and $\left\langle\mathrm{r}_{\mathrm{PO}}\right\rangle$ was found, with

$$
\delta_{\text {iso }}\left(\left\langle\mathrm{r}_{\mathrm{PO}}\right\rangle,\left\langle\theta_{\mathrm{POAl}}\right\rangle\right)=35.64\left\langle\mathrm{r}_{\mathrm{PO}}\right\rangle-1.194\left\langle\theta_{\mathrm{POAl}}\right\rangle+92.27
$$

A plot of the predicted $\delta_{\text {iso }}\left(\left\langle\mathrm{r}_{\mathrm{PO}}\right\rangle,\left\langle\theta_{\mathrm{POAl}}\right\rangle\right)$ against the experimental $\delta_{\text {iso }}$ is shown in Figure $4(\mathrm{c})$. This relationship is different from that reported for calcined AlPOs, ${ }^{54}$ but similar to that derived from computational results as discussed in the Supporting Information (S9). However, all three of the structure-based assignment methods ${ }^{5456}$ lead to the same assignment as that calculated by DFT, with the shifts following the trend P1 > P3 > P2 in all six materials. The finding that ${ }^{31} \mathrm{P} \delta_{\text {iso }}$ can readily be predicted from the crystal structure is likely to be invaluable when considering other AlPOs containing disordered guest species, where a chemically-realistic structural model (a prerequisite for DFT calculations) may be difficult to generate, whereas an average framework structure can generally be determined, even from powder diffraction data.

Unlike the other nuclei investigated in this work, ${ }^{27} \mathrm{Al}$ is quadrupolar ( $\operatorname{spin} \mathrm{I}=5 / 2$ ) and the MAS NMR spectra shown in Figure 3 contain resonances broadened by the second-order quadrupolar interaction. ${ }^{57}$ Therefore, while the octahedral Al1 can readily be distinguished from the tetrahedral Al2 and Al3 on the grounds of their chemical shifts (typically 35 to $50 \mathrm{ppm}$ for tetrahedral $\mathrm{Al}$ and 0 to $-20 \mathrm{ppm}$ for octahedral $\mathrm{Al}^{58}$ ), the resonances from Al2 and Al3 overlap significantly, and cannot be resolved at all for AlPO- 
34(emim) or AlPO-34(cyclam). The multiple-quantum (MQ) MAS experiment ${ }^{59,60}$ yields a two- dimensional spectrum containing an isotropic dimension (free from all anisotropic broadening by the quadrupolar interaction) and a conventional MAS dimension. From the positions of the centre of gravity of the resonances observed, the isotropic chemical shifts and quadrupolar product, $\mathrm{P}_{\mathrm{Q}}\left(=\mathrm{C}_{\mathrm{Q}}\left(1+\left(\eta_{\mathrm{Q}}{ }^{2} / 3\right)\right)^{1 / 2}\right.$, where $\mathrm{C}_{\mathrm{Q}}$ and $\eta_{\mathrm{Q}}$ are the quadrupolar coupling constant and asymmetry parameter, respectively) can be determined, as described in the Supporting Information (S10). The approximate values of $\delta_{\text {iso }}$ and $\mathrm{P}_{\mathrm{Q}}$ extracted from the MQMAS NMR spectra are reported in Table 2. Resonances for all three Al species were fully resolved by MQMAS for all of the samples studied here, except AlPO-34(cyclam), for which only one resonance, corresponding to both Al2 and Al3, was observed (as shown in the Supporting Information (S10)).

\section{Evidence of Dynamics from ${ }^{27} \mathrm{Al} \mathrm{NMR}$}

The ${ }^{27}$ Al NMR spectra in Figure 3 show only the central-transition (CT) resonances for each material. However, where $C_{Q}$ is small and $\eta_{Q}$ is hard to determine from the narrower CT, the shape of the much broader satellite transitions (STs) can provide additional information. The STs are typically broadened over several hundred $\mathrm{kHz}$ and appear as a series of spinning sidebands (SSBs) in MAS spectra. It is, therefore, crucial to set the magic angle precisely to $54.736^{\circ}$ in order to observe the SSB manifold.$^{61}$ Figure 5 shows the ${ }^{27} \mathrm{Al}$ MAS NMR spectra of the six forms of AlPO-34, recorded with a $1 \mathrm{MHz}$ spectral window and an accurately-set rotor angle. For AlPO-34(pyr) and AlPO-34(mor), it was not possible to carry out analysis of the ST SSBs, as each sideband was so broad as to be essentially undetectable. Similarly, although still detectable, the ST SSBs were also broader than expected for AlPO-34(pip) and did not provide any further information on the values of $\mathrm{C}_{\mathrm{Q}}$ or $\eta_{\mathrm{Q}}$. Antonijevic et al. have previously observed broadening of the STs of AlPO-14, and attributed this to microsecond-timescale dynamics of the isopropylammonium SDA inside the pores. This motion leads to a modulation of the electric field gradient (EFG) at the nucleus (responsible for the quadrupolar broadening) and inefficient averaging by MAS. Effects are most pronounced when the timescale of the modulation is similar in 
magnitude to the quadrupolar frequency (given by $\omega_{Q}{ }^{\text {PAS }}=3 \pi C_{Q} / 20$ in $\operatorname{rad~s}^{-1}$ for $\mathrm{I}=5 / 2$ ). The rate of motion would be expected to increase upon heating, enabling line broadenings resulting from dynamics to be distinguished from those arising from static disorder and a distribution of chemical sites. Note that dynamic line broadening may increase or decrease with increased motion/temperature depending on whether the rate of motion is smaller or larger than $\omega_{\mathrm{Q}}{ }^{\mathrm{PAS}}$. The ${ }^{27} \mathrm{Al}$ MAS NMR spectra were also recorded at $373 \mathrm{~K}$ (red lines in Figure 5) and, for AlPO-34(pyr), AlPO-34(pip) and AlPO-34(mor), the very broad ST SSBs narrow as the timescale of the modulation of the EFG becomes greater than $\omega_{Q}{ }^{\text {PAS }}$. In contrast, for AlPO-34(dmim), AlPO-34(emim) and AlPO-34(cyclam), the broadening of the ST SSBs increases at elevated temperature. While determining the precise source of the motion in these materials is beyond the scope of the current work, owing to the polyatomic SDAs involved and the presence of partially-occupied water sites in some of the structures, we offer the following preliminary discussion of this interesting difference in behaviour dependent on the SDA type.

The dynamics present in the ionothermal AlPO-34(dmim) and AlPO-34(emim) appears to be slower (at any given temperature) than in the hydrothermal materials, with the exception of AlPO-34(cyclam). However, while one might initially conclude that this is due to the presence of more conformationally-rigid SDAs in the ionothermally-prepared materials, the behaviours of AlPO-34(pyr), containing a rigid SDA, and AlPO-34(cyclam), containing a flexible SDA, cannot be explained in this way. Alternatively, the $\mathrm{H}_{2} \mathrm{O}$ present in AlPO-34(pip) and AlPO-34(pyr) may be responsible for the more rapid dynamics observed in these materials. If this were the explanation, it would suggest that $\mathrm{H}_{2} \mathrm{O}$ may also be present in AlPO-34(mor), although Harding et $a .^{33}$ did not observe this by diffraction. Thermogravimetric analysis (TGA) of the six samples studied here, and accompanying mass spectrometry (shown in the Supporting Information (S5)) revealed a pre-calcination loss of about $0.6 \mathrm{H}_{2} \mathrm{O}$ per $\mathrm{Al}_{3} \mathrm{P}_{3} \mathrm{O}_{12}$ for AlPO-34(pip), AlPO-34(pyr) and, unexpectedly, also AlPO-34(mor). The other three samples showed negligible mass loss prior to calcination (at about $400-500{ }^{\circ} \mathrm{C}$ ), consistent with anhydrous materials with small amounts of surface moisture. This indicates that motion of the water molecules may be 
responsible for the broadened ST SSBs observed at room temperature. However, we suggest that the motion responsible for the line broadening is not a $\mathrm{C}_{2}$ rotation of the $\mathrm{H}_{2} \mathrm{O}$, which would not alter the ${ }^{27} \mathrm{Al}$ quadrupolar interaction, but rather a hopping between the two adjacent (and equivalent) sites in the structure, shown in Figure 1(b) (in the periodic structure, the distance between these sites is $\sim 1.8 \AA$ ). Such a hopping would lead to an average $P-1$ symmetry, consistent with the three ${ }^{31} \mathrm{P}$ resonances observed in all materials, even those containing $\mathrm{H}_{2} \mathrm{O}$ (which should have local $P 1$ symmetry in any given unit cell). Further investigation of this theory will require either the preparation of deuterated materials and additional experimental measurements or extensive molecular dynamics calculations (running to the microsecond timescale, which is unfeasible on most computational resources). This is a topic to which we hope to return in the future.

$\mathrm{H}_{2} \mathrm{O}$ has not been detected in AlPO-34(mor) previously, but its observation here is consistent with the disorder implied by ${ }^{1} \mathrm{H},{ }^{13} \mathrm{C}$ and ${ }^{15} \mathrm{~N}$ NMR spectroscopy. It is also possible that the preparation and storage history of the sample studied has led to a more hydrated form of the material being characterised here than in the crystallographic studies, $^{33,35}$ as our sample has been exposed to air on the bench for extended periods of time. We have previously observed a similar hydration of JDF-2, which contains methylammonium hydroxide as the SDA. Upon exposure to moist air, JDF-2 converts to AlPO-53(A) and the transformation can be reversed by mild heating. ${ }^{17}$ It is, therefore, plausible that ambient hydration may also occur for AlPO-34(mor). In addition, changes in humidity under different experimental conditions may lead to the differences in $\mathrm{H}_{2} \mathrm{O}$ content observed for AlPO-34(pyr) and AlPO-34(pip) in the XRD, NMR and TGA experiments.

In order to investigate whether the presence of water was, indeed, responsible for the motional broadening of the ST SSBs of AlPO-34(pyr), AlPO-34(pip) and AlPO-34(mor), all six materials were heated to $\sim 110^{\circ} \mathrm{C}$ for at least $24 \mathrm{~h}$ in an attempt to remove any water present (without also removing the SDA and HF). The ${ }^{27} \mathrm{Al}$ MAS NMR spectra of the dried samples were then recorded at 298 and $373 \mathrm{~K}$ and are shown in Figure 6. While no change 
is observed for the three materials believed to be anhydrous: AlPO-34(dmim), AlPO34(emim) and AlPO-34(cyclam), the ST SSBs of AlPO-34(pyr) and AlPO-34(pip) show very different behaviour after drying. While this difference is less pronounced for AlPO34(mor), it is worth noting that the ST SSBs for this sample are visible at $298 \mathrm{~K}$, and slightly sharper at $373 \mathrm{~K}$ after drying. We can, therefore, conclude that water is present in AlPO-34(pyr), AlPO-34(pip) and AlPO-34(mor), and undergoes motion on the microsecond timescale. However, the fact that the linewidths of the ST SSBs are still temperature dependent for all six dried materials indicates that (as might be expected) the SDAs themselves also undergo some motion, on timescales approaching $1 / \omega_{\mathrm{Q}}{ }^{\text {PAS }}$ at higher temperatures.

\section{Conclusions}

We have carried out a detailed NMR spectroscopic characterisation of six forms of asmade AlPO-34, synthesised in the presence of different SDAs. Assignment of the spectra required the use of periodic DFT calculations, which revealed, in the cases of AlPO34(dmim) and AlPO-34(emim), that some dealkylation of the 1,3-alkylimidazolium to a 1alkylimidazolium occurs, giving rise to distinctive downfield ${ }^{1} \mathrm{H}$ resonances. Such species are present in low amounts and, hence, cannot be detected readily by crystallographic diffraction techniques. When assigning the ${ }^{31} \mathrm{P}$ NMR spectra, we demonstrated that the isotropic chemical shift has a marked dependence on both the mean P-O-Al bond angle and the mean $\mathrm{P}-\mathrm{O}$ bond length, in agreement with our recent finding that the assignment of resonances based entirely on the mean P-O-Al bond angle is an overly-simplistic approach. ${ }^{54}$ The work presented here demonstrates an extension of our earlier work, focused on calcined AlPOs, to materials containing disordered SDAs and frameworkbound anions, suggesting that the method may be more generally applicable to AlPOs containing guest molecules; further investigation of this is ongoing.

In all six materials studied, temperature-dependent broadening of the spinning sidebands from the ${ }^{27} \mathrm{Al}$ satellite transitions indicated molecular-scale dynamics on the 
microsecond timescale. Thermogravimetric analysis revealed the presence of water in three of the samples: AlPO-34(pyr), AlPO-34(mor) and AlPO-34(pip). Dehydration of these three materials was shown to change the observed temperature dependence of the broadening, indicating that motion of water within these materials occurs on the microsecond timescale (and is most likely a hopping between the two adjacent water sites in the crystal structures). Interestingly, water has not previously been reported within the structure of AlPO-34(mor), ${ }^{33}$ suggesting that as-made AlPO-34 materials may be hygroscopic, with the ability to take small amounts of water into the pores. We have previously observed such behaviour for the as-made AlPO, JDF-2. ${ }^{17}$ However, as motion was detected in all six materials, including the anhydrous AlPO-34(dmim), AlPO34(emim) and AlPO-34(cyclam), it is clear that dynamics of the SDAs also occurs on the microsecond timescale (as previously observed for AlPO-14 $4^{22}$ ) and further work, for example including molecular dynamics simulations and experimental ${ }^{2} \mathrm{H} N \mathrm{NR}$, will be required in order to characterise these motions more fully.

Relating our results to those of Xin et al., who examined AlPO-34 as a model for understanding the origin of the structure-directing effect, ${ }^{35}$ we have shown how three further SDAs, not considered in their work, are effective for forming the same framework. The structure of AlPO-34(pip) determined here by synchrotron X-ray powder diffraction differs slightly from that of Xin et al. primarily in the position of the $\mathrm{H}_{2} \mathrm{O}$ molecule and the orientation of the SDA. DFT calculations indicate that the structures proposed here were energetically more stable, but it remains unclear whether the disorder in our model AlPO$34($ pip-2b) arises as a consequence of static disorder or dynamics. The two cases are not calculated to be distinguishable on the grounds of isotropic chemical shifts.

Xin et al. ${ }^{35}$ concluded that the SDA-framework binding free energy is the key origin of the structure directing effect. Our work also reveals that water may be included in the porous structure, along with the SDA, depending on synthesis route, and that the amount of water may vary with time once the sample has been isolated and exposed to the atmosphere. The observation of motional effects on the ${ }^{27} \mathrm{Al}$ NMR spectra illustrates the 
conformational and structural flexibility of the AlPO structure and the SDA and water contained within, which in turn implies some greater complexity in the role of the structure-directing agent, with the subtle effect of co-occluded water needing to be considered. The water may be hydrogen bonded to both the AlPO framework and the SDA so its role must also be taken into account to explain fully the interactions leading to the crystallisation of a particular structure type.

\section{Supporting Information}

The Supporting Information is available free of charge on the ACS Publications website at DOI: XXX. Synthetic details, powder X-ray diffraction patterns, atomic numbering schemes, structure solution of AlPO-34(pip), thermogravimetric analysis, modelling disorder in AlPO-34, full assignment of the ${ }^{1} \mathrm{H},{ }^{13} \mathrm{C}$ and ${ }^{15} \mathrm{~N}$ NMR spectra of AlPO-34, twodimensional ${ }^{19} \mathrm{~F}$ NMR spectrum of AlPO-34(cyclam), relating the local structure of AlPO34 to ${ }^{31} \mathrm{P}$ chemical shifts, and one- and two-dimensional ${ }^{27} \mathrm{Al}$ NMR spectra.

\section{Acknowledgements}

SEA would like to thank the Leverhulme Trust (F/00 268/BJ) and EPSRC for computational support through the Collaborative Computational Project on NMR Crystallography (CCP-NC), via EP/M022501/1). SEA would also like to thank the Royal Society and Wolfson Foundation for a merit award. MA and RIW would like to acknowledge financial support from the EPSRC (EP/C516591), as would SW (GR/T23824). We thank the ESRF for access to station ID31 for the acquisition of the highresolution powder XRD pattern (CH2707 experiment) and Dr Irene Margiolaki and Dr Franck Millange for assistance with data collection. Dr Ben Douglas and Mr David Hammond are thanked for assistance with measuring thermogravimetric analysis. The research data (and/or materials) supporting this publication can be accessed at DOI: 10.17630/a6d6d27b-a8f0-46cb-8e6b-2c9a344e86b7. 


\section{References}

1. Davis, M. E.; Lobo, R. F. Zeolite and Molecular Sieve Synthesis. Chem. Mater. 1992, 4, 756-768.

2. Lobo, R. F.; Zones, S. I.; Davis, M. E. Structure-Direction in Zeolite Synthesis. J. Incl. Phenom. Mol. Recogn. Chem. 1995, 21, 47-78.

3. $\mathrm{Yu}, \mathrm{J} . ; \mathrm{Xu}, \mathrm{R}$. Rational Approaches toward the Design and Synthesis of Zeolitic Inorganic Open-Framework Materials. Acc. Chem. Res. 2010, 43, 1195-1204.

4. Wilson, S. T.; Lok, B. M.; Messina, C. A.; Cannan, T. R.; Flanigen, E. M. Aluminophosphate Molecular Sieves: A new Class of Microporous Crystalline Inorganic Solids. J. Am. Chem. Soc. 1982, 104, 1146-1147.

5. Cheetham, A. K.; Férey, G.; Loiseau, T. Open-Framework Inorganic Materials. Angew. Chem. Int. Ed. 1999, 38, 3268-3292.

6. Lok, B. M.; Cannan, T. R.; Messina, C. A. The Role of Organic Molecules in Molecular Sieve Synthesis. Zeolites 1983, 3, 282-291.

7. Lee, H.; Zones, S. I.; Davis, M. E. A Combustion-Free Methodology for Synthesizing Zeolites and Zeolite-Like Materials. Nature 2003, 425, 385-388.

8. Jackowski, A.; Zones, S. I.; Hwang, S. J.; Burton, A. W. Diquaternary Ammonium Compounds in Zeolite Synthesis: Cyclic and Polycyclic N-Heterocycles Connected by Methylene Chains. J. Am. Chem. Soc. 2009, 131, 1092-1100.

9. Lewis, D. W.; Freeman, C. M.; Catlow, C. R. A. Predicting the Templating Ability of Organic Additives for the Synthesis of Microporous Materials. J. Phys. Chem. 1995, 99, 11194-11202.

10. Lewis, D. W.; Willock, D. J.; Catlow, C. R. A.; Thomas, J. M.; Hutchings, G. J. De Novo Design of Structure-Directing Agents for the Synthesis of Microporous Solids. Nature 1996, 382, 604-606.

11. Castro, M.; Seymour, V. R.; Carnevale, D.; Griffin, J. M.; Ashbrook, S. E.; Wright, P. A.; Apperley, D. C.; Parker, J. E.; Thompson, S. P.; Fecant, A. et al. Molecular Modeling, Multinuclear NMR, and Diffraction Studies in the Templated Synthesis 
and Characterization of the Aluminophosphate Molecular Sieve STA-2. J. Phys. Chem. C 2010, 114, 12698-12710.

12. Huang, Y.; Richter, R.; Kirby, C. W. Characterization of the Gel Phases of $\mathrm{AlPO}_{4}-11$ Molecular Sieve Synthesis by Solid-State NMR. J. Phys. Chem. B 2003, 107, 13261337.

13. Cundy, C. S.; Cox, P. A. The Hydrothermal Synthesis of Zeolites: Precursors, Intermediates and Reaction Mechanism. Micropor. Mesopor. Mater. 2005, 82, 1-78.

14. Ashbrook, S. E.; Dawson, D. M.; Griffin, J. M. in Local Structural Characterisation, Bruce, D. W., O’Hare, D., Walton, R. I., Eds.; Wiley, Chichester, UK, 2013; pp 1-88.

15. Ashbrook, S. E.; Dawson, D. M.; Seymour, V. R. Recent Developments in Solid-State NMR Spectroscopy of Crystalline Microporous Materials. Phys. Chem. Chem. Phys. 2014, 16, 8223-8242.

16. Apperley, D. C.; Harris, R. K.; Hodgkinson, P. Solid State NMR Momentum Press, New York, NY 2012.

17. Ashbrook, S. E.; Cutajar, M.; Griffin, J. M.; Lethbridge, Z. A. D.; Walton, R. I.; Wimperis, S. Transformation of AlPO-53 to JDF-2: Reversible Dehydration of a Templated Aluminophosphate Studied by MAS NMR and Diffraction. J. Phys. Chem. C 2009, 113, 10780-10789.

18. Seymour, V. R.; Eschenschroeder, E. C. V.; Castro, M.; Wright, P. A.; Ashbrook, S. E. Application of NMR Crystallography to the Determination of the Mechanism of Charge-Balancing in Organocation-Templated AlPO STA-2. CrystEngComm 2013, $15,8668-8679$.

19. Seymour, V. R.; Eschenroeder, E. C. V.; Wright, P. A.; Ashbrook, S. E. An NMR Crystallographic Approach to Monitoring Cation Substitution in the Aluminophosphate STA-2. Solid State Nucl. Magn. Reson. 2015, 65, 64-74.

20. Martineau, C.; Bouchevereau, B.; Tian, Z.; Lohmeier, S.-J.; Behrens, P.; Taulelle, F. Beyond the Limits of X-ray Powder Diffraction: Description of the Nonperiodic Subnetworks in Aluminophosphate-Cloverite by NMR Crystallography. Chem. Mater. 2011, 23, 4799-4808. 
21. Martineau, C.; Mellot-Draznieks, C.; Taulelle, F. NMR Crystallography of $\mathrm{AlPO}_{4^{-}}$ CJ2: From the Topological Network to the Local $(\mathrm{OH}) / \mathrm{F}$ Distribution. Phys. Chem. Chem. Phys. 2011, 13, 18078-18087.

22. Antonijevic, S.; Ashbrook, S. E.; Biedasek, S.; Walton, R. I.; Wimperis, S.; Yang, H. X. Dynamics on the Microsecond Timescale in Microporous Aluminophosphate AlPO14 as Evidenced by ${ }^{27} \mathrm{Al}$ MQMAS and STMAS NMR Spectroscopy. J. Am. Chem. Soc. 2006, 128, 8054-8062.

23. Baerlocher, C.; McCusker, L. B. Database of Zeolite Structures, http://www.izastructure.org/databases/.

24. Kang, L.; Zhang, T.; Liu, Z.; Han, K.-L. Methanol Adsorption in Isomorphously Substituted AlPO-34 Clusters and Periodic Density Functional Theory Calculations. J. Phys. Chem. C 2008, 112, 5526-5532.

25. Dai, W.; Wang, X.; Wu, G.; Li, L.; Guan, N.; Hunger, M. Methanol-to-Olefin Conversion Catalyzed by Low-Silica AlPO-34 with Traces of Brønsted Acid Sites: Combined Catalytic and Spectroscopic Investigations. ChemCatChem 2012, 4, 14281435.

26. Woodcock, D. A.; Lightfoot, P.; Villaescusa, L. A.; Diaz-Cabanas, M. J.; Camblor, M. A.; Engberg, D. Negative Thermal Expansion in the Siliceous Zeolites Chabazite and ITQ-4: A Neutron Powder Diffraction Study. Chem. Mater. 1999, 11, 2508-2514.

27. Martinez-Iñesta, M. M.; Lobo, R. F. Investigation of the Negative Thermal Expansion Mechanism of Zeolite Chabazite Using the Pair Distribution Function Method. J. Phys. Chem. B 2005, 109, 9389-9396.

28. Amri, M.; Walton, R. I. Negative Thermal Expansion in the Aluminum and Gallium Phosphate Zeotypes with CHA and AEI Structure Types. Chem. Mater. 2009, 21, 3380-3390.

29. Cooper, E. R.; Andrews, C. D.; Wheatley, P. S.; Webb, P. B.; Wormald, P.; Morris, R. E. Ionic Liquids and Eutectic Mixtures as Solvent and Template in Synthesis of Zeolite Analogues. Nature 2004, 430, 1012-1016. 
30. Parnham, E. R.; Morris, R. E. 1-Alkyl-3-methyl Imidazolium Bromide Ionic Liquids in the Ionothermal Synthesis of Aluminium Phosphate Molecular Sieves. Chem. Mater. 2006, 18, 4882-4887.

31. Oliver, S.; Kuperman, A.; Lough, A.; Ozin, G. A. Synthesis and Characterization of a Fluorinated Anionic Aluminophosphate Framework UT-6, and its HighTemperature Dehydrofluorination to $\mathrm{AlPO}_{4}-\mathrm{CHA}$. J. Mater. Chem. 1997, 7, 807-812.

32. Tuel, A.; Caldarelli, S.; Meden, A.; McCusker, L. B.; Baerlocher, C.; Ristic, A.; Rajic, N.; Mali, G.; Kaucic, V. NMR Characterization and Rietveld Refinement of the Structure of Rehydrated $\mathrm{AlPO}_{4}-34$. J. Phys. Chem. B 2000, 104, 5697-5705.

33. Harding, M. M.; Kariuki, B. M. Microcrystal Structure Determination of $\mathrm{AIPO}_{4}^{-}$ CHA Using Synchrotron Radiation. Acta Crystallogr. 1994, C50, 852-854.

34. Wheatley, P. S.; Morris, R. E. Cyclam as a Structure-Directing Agent in the Crystallization of Aluminophosphate Open Framework Materials from Fluoride Media. J. Solid State Chem. 2002, 167, 267-273.

35. Xin, L.; Sun, H.; Xu R.; Yan, W. Origin of the Structure-Directing Effect Resulting in Identical Topological Open-Framework Materials. Sci. Rep. 2015, 5, 14940.

36. Pike, K. J.; Malde, R. P.; Ashbrook, S. E.; McManus, J.; Wimperis, S. MultipleQuantum MAS NMR of Quadrupolar Nuclei. Do Five-, Seven- and Nine-Quantum Experiments Yield Higher Resolution than the Three-Quantum Experiment? Solid State Nucl. Magn. Reson. 2000, 16, 203-215.

37. Skibsted, J.; Jakobsen, H. J. Variable-Temperature ${ }^{87} \mathrm{Rb}$ Magic-Angle Spinning NMR Spectroscopy of Inorganic Rubidium Salts. J. Phys. Chem. A 1999, 103, 7958-7971.

38. Clark, S. J.; Segall, M. D.; Pickard, C. J.; Hasnip, P. J.; Probert, M. J.; Refson, K.; Payne, M. C. First Principles Methods Using CASTEP. Z. Kristallogr. 2005, 220, 567570 .

39. Pickard, C. J.; Mauri, F. All-Electron Magnetic Response with Pseudopotentials: NMR Chemical Shifts. Phys. Rev. B 2001, 63, 245101.

40. Yates, J. R.; Pickard, C. J.; Mauri, F. Calculation of NMR Chemical Shifts for Extended Systems Using Ultrasoft Pseudopotentials. Phys. Rev. B 2007, 76, 024401. 
41. Grimme, S. Semiempirical GGA-Type Density Functional Constructed with a LongRange Dispersion Correction. J. Comput. Chem. 2006, 27, 1789-1799.

42. McNellis, E. R.; Meyer, J.; Reuter, K. Azobenzene at Coinage Metal Surfaces: Role of Dispersive van der Waals Interactions. Phys. Rev. B 2009, 80, 205414.

43. Pyykkö, P. Year-2008 Nuclear Quadrupole Moments. Mol. Phys. 2008, 106, 19651974.

44. Schott-Darie, C.; Kessler, H.; Benazzi, E. Further Results in the Synthesis of Microprous Alumino- and Gallophosphates in the Presence of Fluoride. Stud. Surf. Sci. Catal. 1994, 83, 3-10.

45. Rajic, N.; Gabrovsek, R.; Ristic, A.; Kaucic, V. Thermal Investigations of Some AlPO and MeAPO Materials Prepared in the Presence of HF. Thermochim. Acta 1997, 306, 31-36.

46. Charpentier, T. The PAW/GIPAW Approach for Computing NMR Parameters: A new Dimension Added to NMR Study of Solids. Solid State Nucl. Magn. Reson. 2011, 40, 1-20.

47. Bonhomme, C.; Gervais, C.; Babonneau, F.; Coelho, C.; Pourpoint, F.; Azaïs, T.; Ashbrook, S. E.; Griffin, J. M.; Yates, J. R.; Mauri, F. et al. First-Principles Calculation of NMR Parameters Using the Gauge Including Projector Augmented Wave Method: A Chemist's Point of View. Chem. Rev. 2012, 112, 5733-5779.

48. Ashbrook, S. E.; Dawson, D. M. Exploiting Periodic First-Principles Calculations in NMR Spectroscopy of Disordered Solids. Acc. Chem. Res. 2013, 46, 1964-1974.

49. Ashbrook, S. E.; McKay, D. Combining Solid-State NMR Spectroscopy with FirstPrinciples Calculations - a Guide to NMR Crystallography. Chem. Commun. 2016, $52,7186-7204$.

50. Sneddon, S.; Dawson, D. M.; Pickard, C. J.; Ashbrook, S. E. Calculating NMR Parameters in Aluminophosphates: Evaluation of Dispersion Correction Schemes. Phys. Chem. Chem. Phys. 2014, 16, 2660-2673.

51. Griffin, J. M.; Clark, L.; Seymour, V. R.; Aldous, D. W.; Dawson, D. M.; Iuga, D.; Morris, R. E.; Ashbrook, S. E. Ionothermal ${ }^{17} \mathrm{O}$ Enrichment of Oxides Using Microlitre Quantities of Labelled Water. Chem. Sci. 2012, 3, 2293-2300. 
52. Amri, M.; Ashbrook, S. E.; Dawson, D. M.; Griffin, J. M.; Walton, R. I.; Wimperis, S. A Multinuclear Solid-State NMR Study of Templated and Calcined Chabazite-Type GaPO-34. J. Phys. Chem. C 2012, 116, 15048-15057.

53. Massiot, D.; Fayon, F.; Capron, M.; King, I.; Le Calvé, S.; Alonso, B.; Durand, J.-O.; Bujoli, B.; Gan, Z.; Hoatson, G. Modelling One- and Two-Dimensional Solid-State NMR Spectra. Magn. Reson. Chem. 2002, 40, 70-76.

54. Dawson, D. M.; Ashbrook, S. E. Investigating Relationships between the Crystal Structure and ${ }^{31} \mathrm{P}$ Isotropic Chemical Shifts in Calcined Aluminophosphates. J. Phys. Chem. C 2014, 118, 23285-23296.

55. Müller, D.; Jahn, E.; Ladwig, G.; Haubenreisser, U. High-Resolution Solid-State ${ }^{27} \mathrm{Al}$ and ${ }^{31} \mathrm{P}$ NMR: Correlation between Chemical Shift and Mean Al-O-P Angle in $\mathrm{AlPO}_{4}$ Polymorphs. Chem. Phys. Lett. 1984, 109, 332-336.

56. Kanehashi, K.; Nemoto, T.; Saito, K. Through-Bond and Through-Space Connectivities of Amorphous Aluminophosphate by Two-Dimensional ${ }^{27} \mathrm{Al}-{ }^{31} \mathrm{P}$ Heteronuclear NMR. J. Non-Cryst. Solids 2007, 353, 4227-4231.

57. Ashbrook, S. E.; Sneddon, S. New Methods and Applications in Solid-State NMR Spectroscopy of Quadrupolar Nuclei. J. Am. Chem. Soc. 2014, 136, 15440-15456.

58. MacKenzie, K. J. D.; Smith, M. E. Multinuclear Solid-State NMR of Inorganic Materials, $1^{\text {st }}$ edn, Elsevier Science Ltd, Oxford, UK, 2002.

59. Frydman, L.; Harwood, J. S. Isotropic Spectra of Half-Integer Quadrupolar Spins from Bidimensional Magic-Angle Spinning NMR. J. Am. Chem. Soc. 1995, 117, 53675368.

60. Medek, A.; Harwood, J. S.; Frydman, L. Multiple-Quantum Magic-Angle Spinning NMR: A new Method for the Study of Quadrupolar Nuclei in Solids. J. Am. Chem. Soc. $1995,117,12779-12787$.

61. Ashbrook, S. E.; Wimperis, S. High-Resolution NMR of Quadrupolar Nuclei in Solids: The Satellite-Transition Magic Angle Spinning (STMAS) Experiment. Prog. Nucl. Magn. Reson. Spectrosc. 2004, 45, 53-108. 
Table 1. Selected crystallographic parameters for the two possible models of AlPO-34(pip) determined here. Both models have the same unit cell, but AlPO-34(pip-1) has a single orientation of the cations, whereas AlPO-34(pip-2) was refined with two possible cation orientations. See the Supporting Information (S4) for full details.

\begin{tabular}{|c|c|}
\hline Empirical formula & $\mathrm{Al}_{3} \mathrm{P}_{3} \mathrm{FO}_{12.4} \mathrm{C}_{5} \mathrm{H}_{12.8} \mathrm{~N}$ \\
\hline$M_{\mathrm{r}}$ & 478.18 \\
\hline Crystal system & Triclinic \\
\hline Space group & $P \overline{1}$ \\
\hline$a / \AA$ & $9.38191(5)$ \\
\hline$b / \AA$ & $9.16437(5)$ \\
\hline$c / \AA$ & $9.19177(7)$ \\
\hline$\alpha\left(^{\circ}\right)$ & $87.7602(6)$ \\
\hline$\beta\left(^{\circ}\right)$ & $102.0428(7)$ \\
\hline$\gamma\left(\left(^{\circ}\right)\right.$ & $93.4886(6)$ \\
\hline$V / \AA^{3}$ & 771.195(9) \\
\hline Z & 2 \\
\hline$\lambda / \AA$ & 0.79993 \\
\hline Number of reflections & 2431 \\
\hline Num. of fitted structural & 100 \\
\hline Num. of soft restraints & 24 \\
\hline AlPO-34(pip-2) & $0.076,0.101$ \\
\hline AlPO-34(pip-1) & $0.076,0.102$ \\
\hline$R_{\text {Bragg }}, G o F \quad$ AlPO-34(pip-2) & $0.037,2.646$ \\
\hline AlPO-34(pip-1) & $0.039,2.668$ \\
\hline
\end{tabular}


Table 2. The approximate mean chemical shifts, $\delta_{\text {iso }}$ (in ppm) and quadrupolar products, $\mathrm{P}_{\mathrm{Q}^{\prime}}$ (in $\mathrm{MHz}$ ) of the $\mathrm{Al}$ species in the six samples of AlPO-34.

\begin{tabular}{|c|c|c|c|c|c|c|}
\hline \multirow{2}{*}{ SDA } & \multicolumn{2}{|c|}{ Al1 } & \multicolumn{2}{|c|}{$\mathrm{A} 12$} & \multicolumn{2}{|c|}{$\mathrm{Al} 3$} \\
\hline & $\left\langle\delta_{\text {iso }}\right\rangle(\mathrm{ppm})$ & $\left\langle\mathrm{P}_{\mathrm{Q}}\right\rangle / \mathrm{MHz}$ & $\left\langle\delta_{\text {iso }}\right\rangle(\mathrm{ppm})$ & $\left\langle\mathrm{P}_{\mathrm{Q}}\right\rangle / \mathrm{MHz}$ & $\left\langle\delta_{\text {iso }}\right\rangle(\mathrm{ppm})$ & $\left\langle\mathrm{P}_{\mathrm{Q}}\right\rangle / \mathrm{MHz}$ \\
\hline dmim & -5.1 & 2.2 & 46.7 & 2.3 & 46.5 & 4.4 \\
\hline emim & -4.8 & 2.2 & 45.4 & 2.0 & 46.8 & 3.5 \\
\hline pyr & -4.0 & 1.3 & 43.9 & 2.1 & 47.0 & 2.5 \\
\hline pip & -4.5 & 2.1 & 42.7 & 2.9 & 46.0 & 3.1 \\
\hline mor & -4.0 & 1.9 & 43.6 & 2.1 & 48.0 & 2.6 \\
\hline cyclam $^{a}$ & -5.0 & 1.7 & 44.6 & 2.9 & & \\
\hline
\end{tabular}



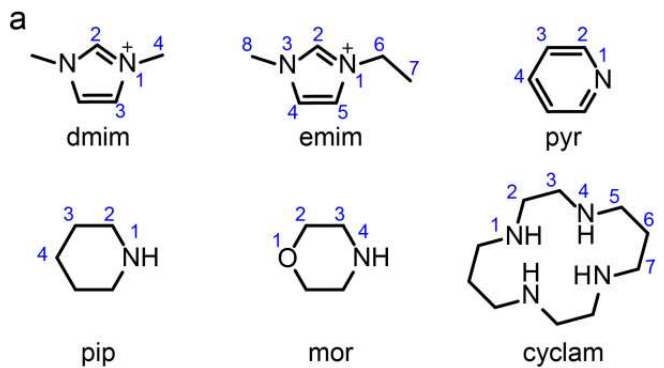

pip

mor

b

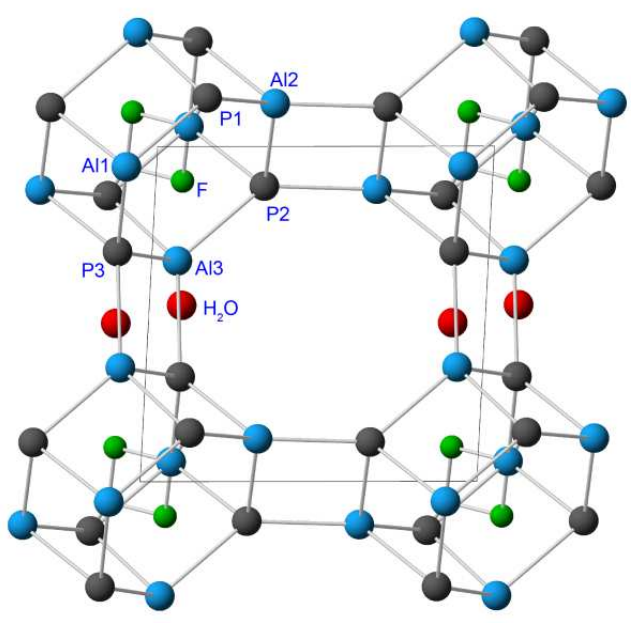

Figure 1. (a) The structures of the six SDAs used, along with the atomic numbering schemes (N.B. N1 and N4 are equivalent in neutral cyclam, but when the molecule is protonated, as in AlPO-34(cyclam), N1 is protonated and N4 is neutral). (b) Schematic representation of the structure of $\mathrm{AlPO}-34$, showing the $\left[\mathrm{Al}_{3} \mathrm{P}_{3} \mathrm{O}_{12} \mathrm{~F}\right]^{-}$framework. The position of $\mathrm{O}$ atoms of the partially-occupied $\mathrm{H}_{2} \mathrm{O}$ molecules (in all structures apart from that for AlPO-34(pip) reported by Xin et al..$^{35}$ ) are indicated. The numbering scheme used for $\mathrm{Al}$ (blue) and $\mathrm{P}$ (grey) atoms is shown, with further details and the numbering scheme for the framework $\mathrm{O}$ atoms given in the Supporting Information (S3). 

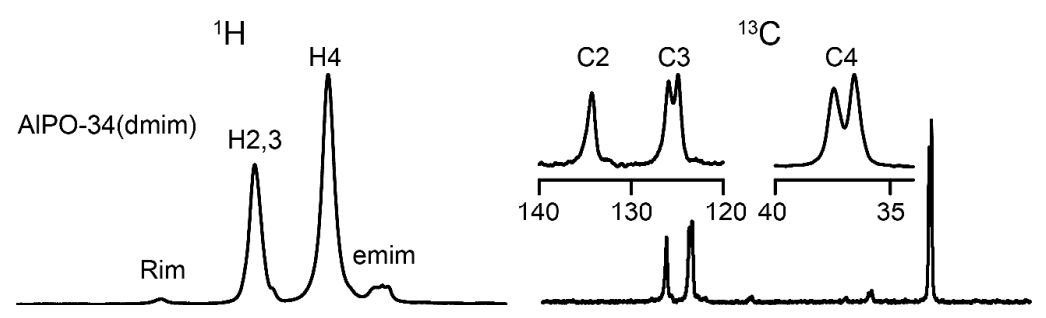

${ }^{15} \mathrm{~N}$
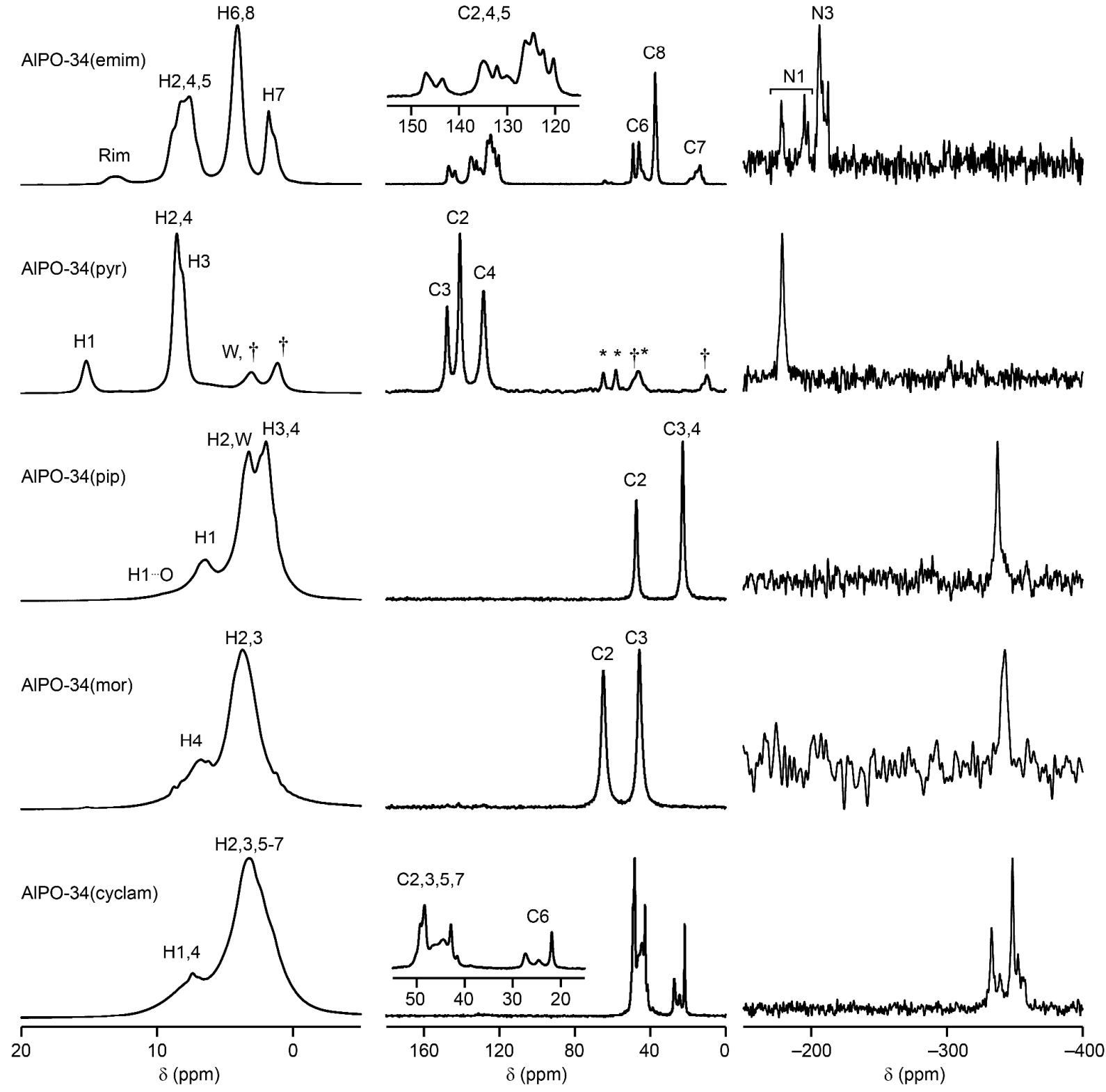

Figure 2. ${ }^{1} \mathrm{H}\left(14.1 \mathrm{~T}, 55 \mathrm{kHz}\right.$ MAS), ${ }^{13} \mathrm{C}\left(14.1 \mathrm{~T}, 12.5 \mathrm{kHz} \mathrm{CP}\right.$ MAS) and ${ }^{15} \mathrm{~N}(9.4 \mathrm{~T}, 5 \mathrm{kHz} \mathrm{CP}$ MAS) NMR spectra of the samples of AlPO-34 studied in this work. Insets show expansions of relevant regions of the spectra, Rim denotes signals from NH of 1alkylimidazolium species in AlPO-34(dmim) and AlPO-34(emim), asterisks denote spinning sidebands, daggers $(\dagger)$ denote ${ }^{1} \mathrm{H}$ and ${ }^{13} \mathrm{C}$ signals from $\mathrm{Et}_{3} \mathrm{~N}$ present in AlPO- 
34(pyr) and $\mathrm{W}$ denotes ${ }^{1} \mathrm{H}$ signals from $\mathrm{H}_{2} \mathrm{O}$ in AlPO-34(pyr) and AlPO-34(pip). The indicated assignments of ${ }^{1} \mathrm{H},{ }^{13} \mathrm{C}$ and ${ }^{15} \mathrm{~N}$ resonances are discussed in the text. 

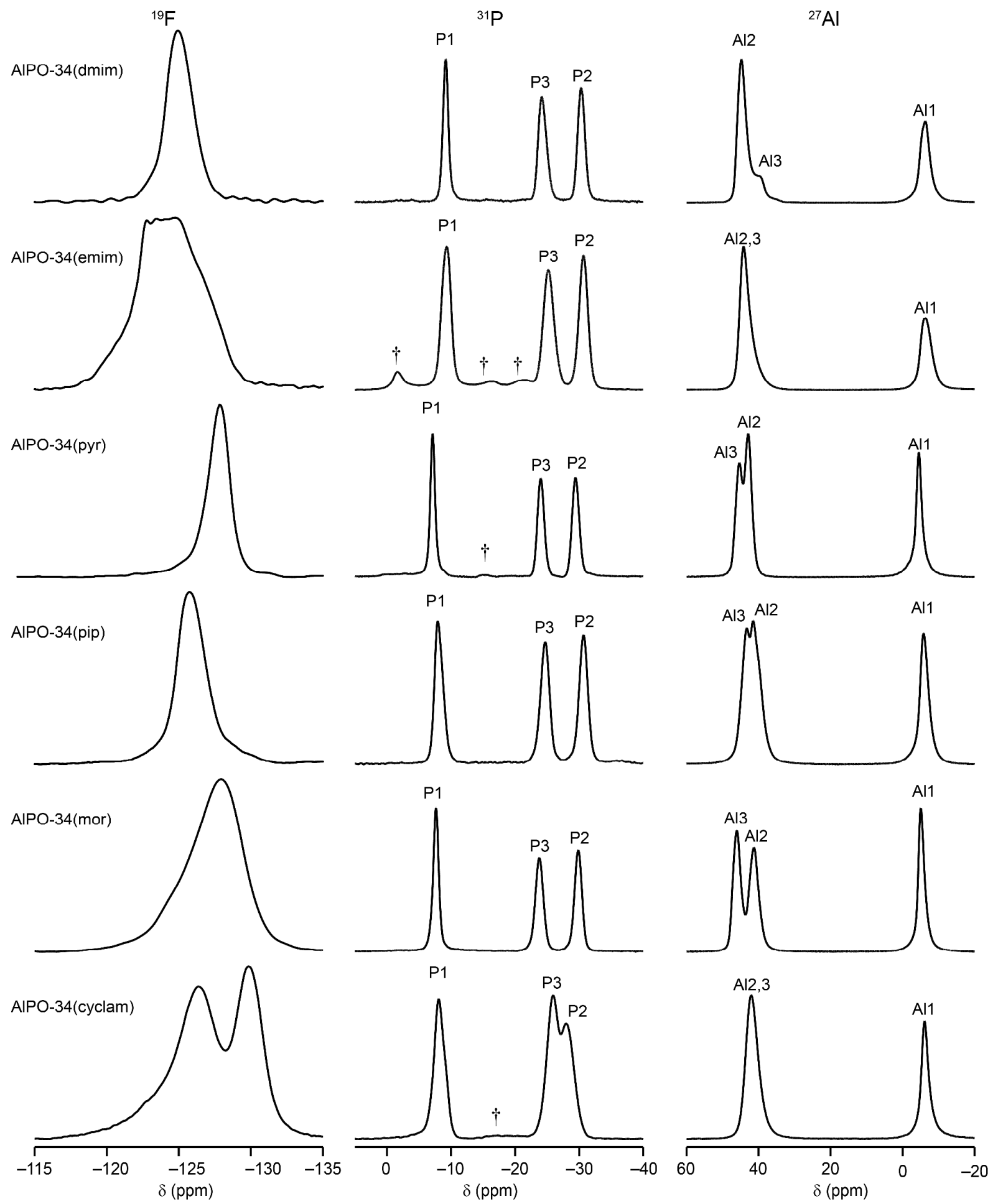

Figure 3. ${ }^{19} \mathrm{~F}\left(14.1 \mathrm{~T}, 55 \mathrm{kHz}\right.$ MAS), ${ }^{31} \mathrm{P}\left(14.1 \mathrm{~T}, 14 \mathrm{kHz}\right.$ MAS) and ${ }^{27} \mathrm{Al}(14.1 \mathrm{~T}, 12.5 \mathrm{kHz}$ MAS) NMR spectra of the samples of AlPO-34 studied in this work. The indicated assignments of ${ }^{31} \mathrm{P}$ and ${ }^{27} \mathrm{Al}$ resonances are discussed in the text. Daggers $(\dagger)$ denote unassigned ${ }^{31} \mathrm{P}$ resonances. 
a

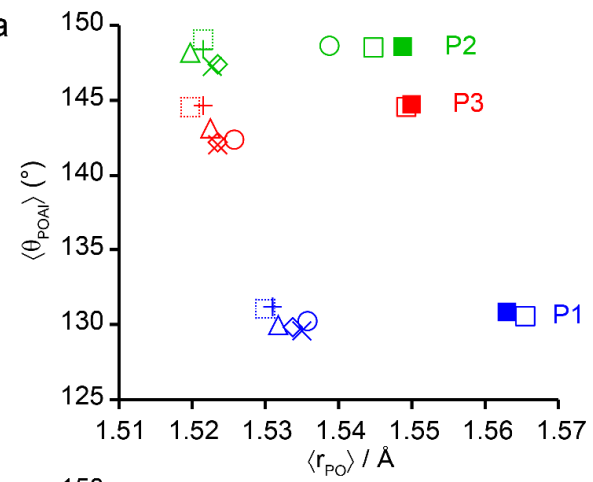

b

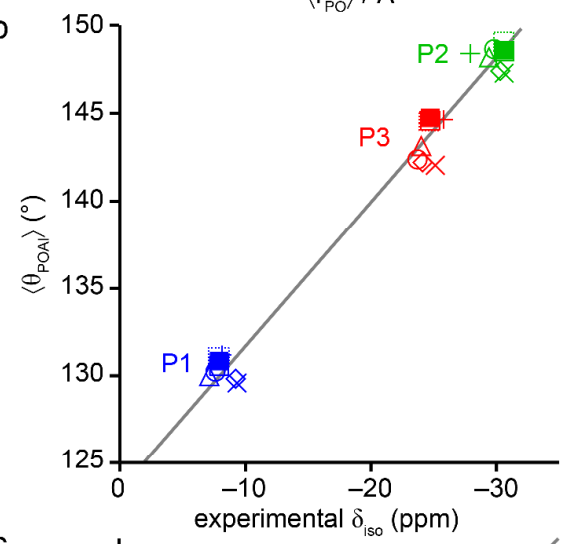

C

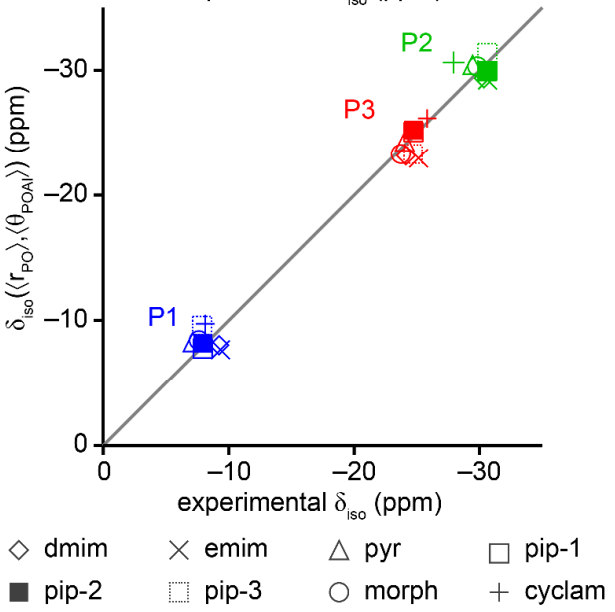

Figure 4. Plots of (a) experimental $\left\langle\theta_{\mathrm{POAl}}\right\rangle$ against experimental $\left\langle\mathrm{r}_{\mathrm{PO}}\right\rangle$ for the three distinct $\mathrm{P}$ species in each of the six structures of as-made AlPO-34 studied here, (b) experimental $\left\langle\theta_{\mathrm{POAl}}\right\rangle$ against experimental $\delta_{\text {iso }}$ for the six forms of AlPO-34 and (c) $\delta_{\text {iso }}\left(\left\langle\mathrm{r}_{\mathrm{PO}}\right\rangle,\left\langle\theta_{\mathrm{POAl}}\right\rangle\right)$ (Equation 2) against experimental $\delta_{\text {iso }}$ for the six forms of AlPO-34. The grey line in (b) indicates Equation 1 and the grey line in (c) indicates an ideal $1: 1$ correspondence. For further details on determining $\delta_{\mathrm{iso}}\left(\left\langle\mathrm{r}_{\mathrm{PO}}\right\rangle,\left\langle\theta_{\mathrm{POAl}}\right\rangle\right)$, see the Supporting Information (S9) and Ref. 54. 

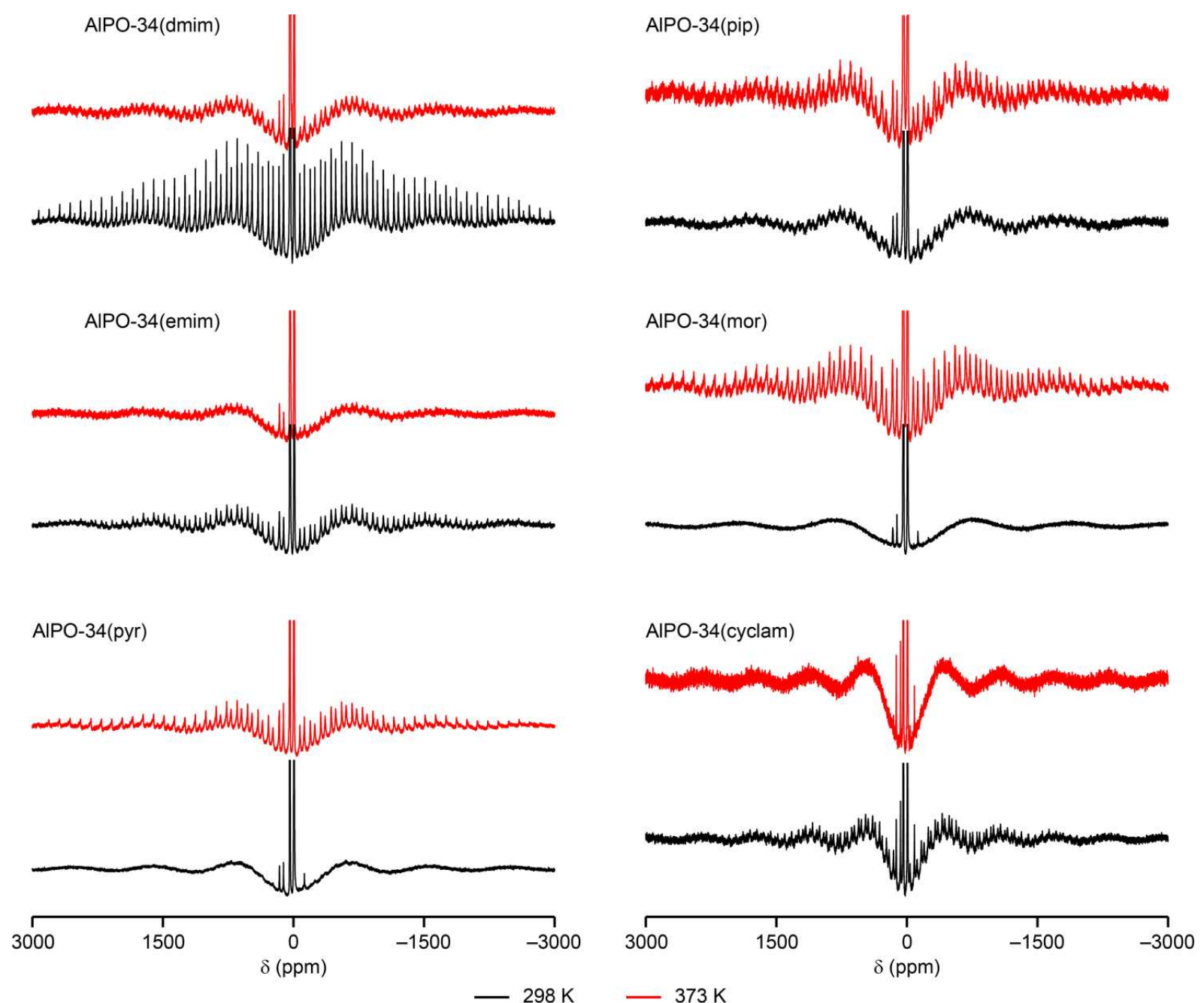

Figure $5 .{ }^{27} \mathrm{Al}(14.1 \mathrm{~T}, 12.5 \mathrm{kHz}$ MAS) NMR spectra of the six forms of AlPO-34, recorded at $298 \mathrm{~K}$ (black) and $373 \mathrm{~K}$ (red) with experimental parameters optimised for observation of the STs as described in the Experimental Details. The CT is truncated in all spectra, but is shown in the Supporting Information (S10). 

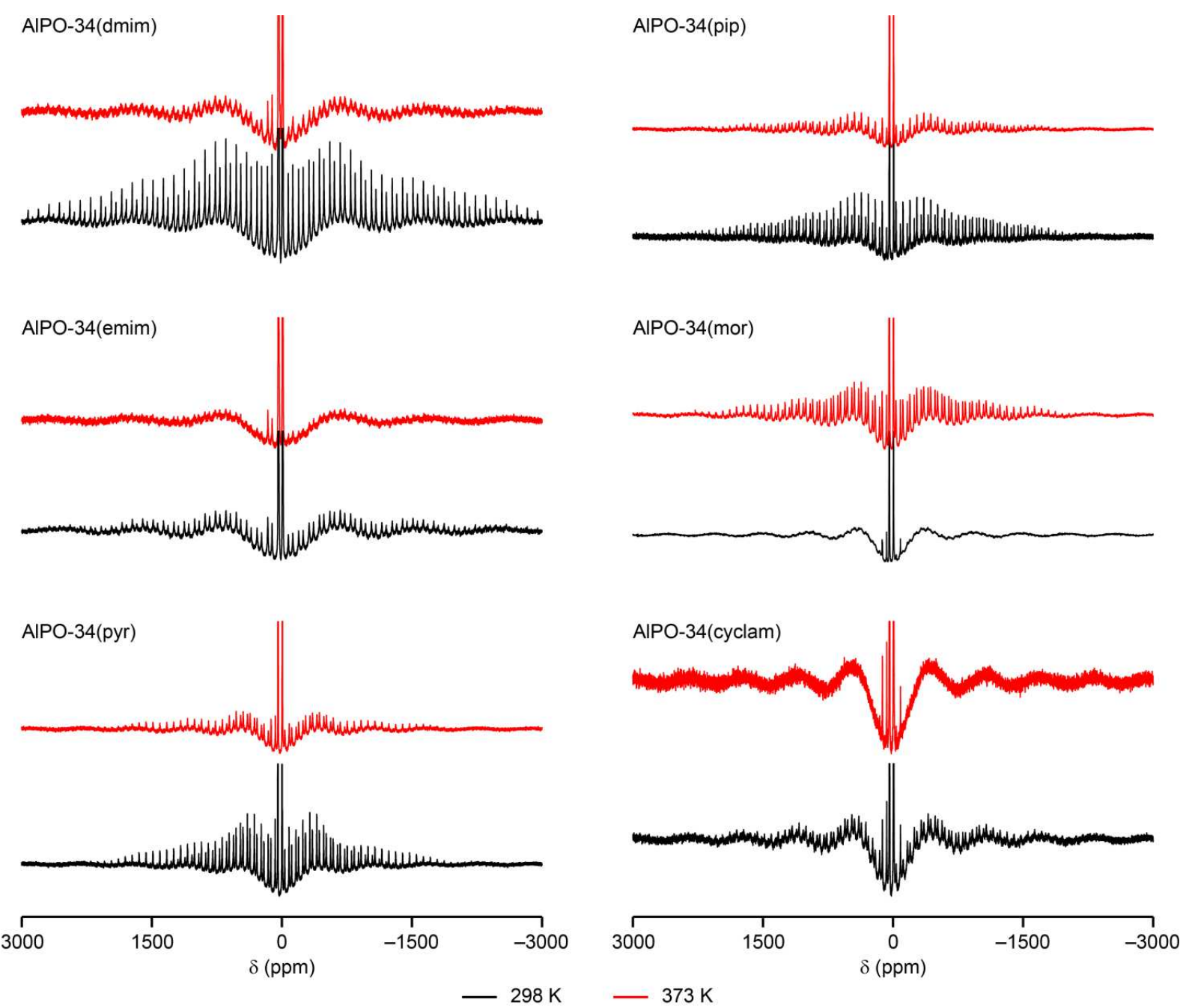

Figure 6. ${ }^{27} \mathrm{Al}(14.1 \mathrm{~T}, 12.5 \mathrm{kHz}$ MAS) NMR spectra of the six forms of AlPO-34 after drying, recorded at $298 \mathrm{~K}$ (black) and $373 \mathrm{~K}$ (red) with experimental parameters optimised for observation of the STs as described in the Experimental Details. The CT is truncated in all spectra, but is shown in the Supporting Information (S10). 


\section{TOC Graphic}

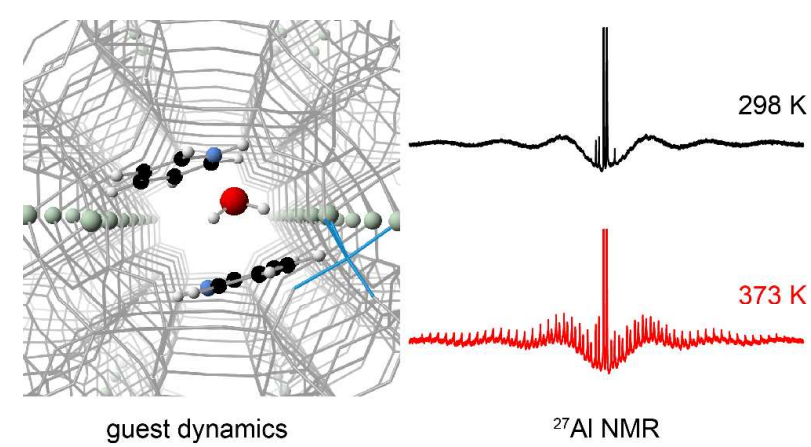

18

19

20

21

22

23

24

25

26

27

28

29

30

31

32

33

34

35

36

37

38

39

40

41

42

43

44

45

46

47

48

49

50

51

52

53

54

55

56

57

58

59

60 
a<smiles>Cn1cc[n+](C)c1</smiles>
dmim<smiles>C1CCNCC1</smiles>
pip

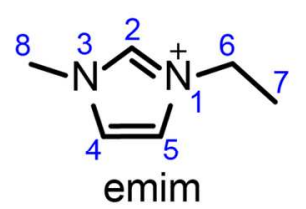<smiles>C1COCCN1</smiles>

mor

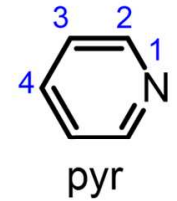<smiles>C1CCNCCNCCCNCCCNC1</smiles>

cyclam

b

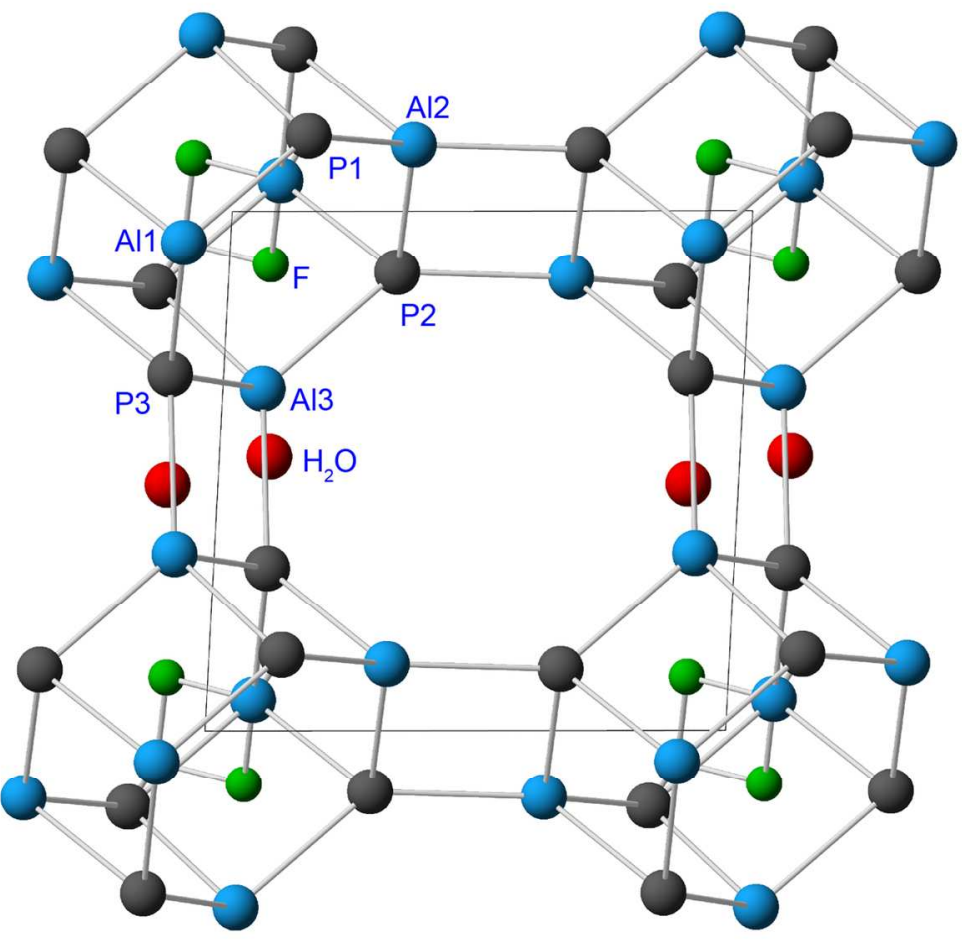

$108 \times 169 \mathrm{~mm}(300 \times 300 \mathrm{DPI})$ 

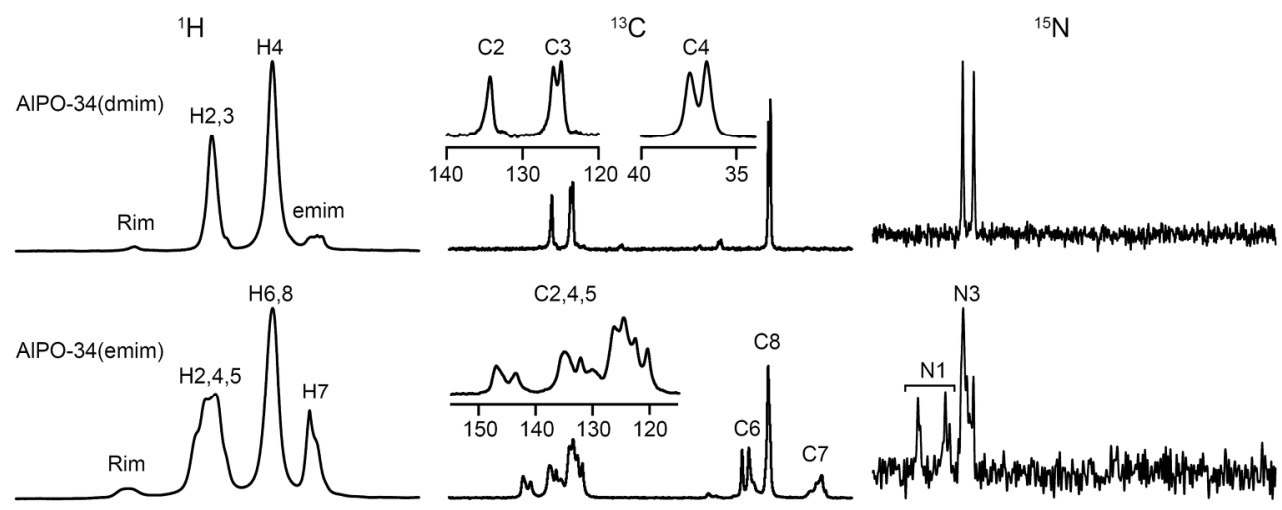

14

15

16

17
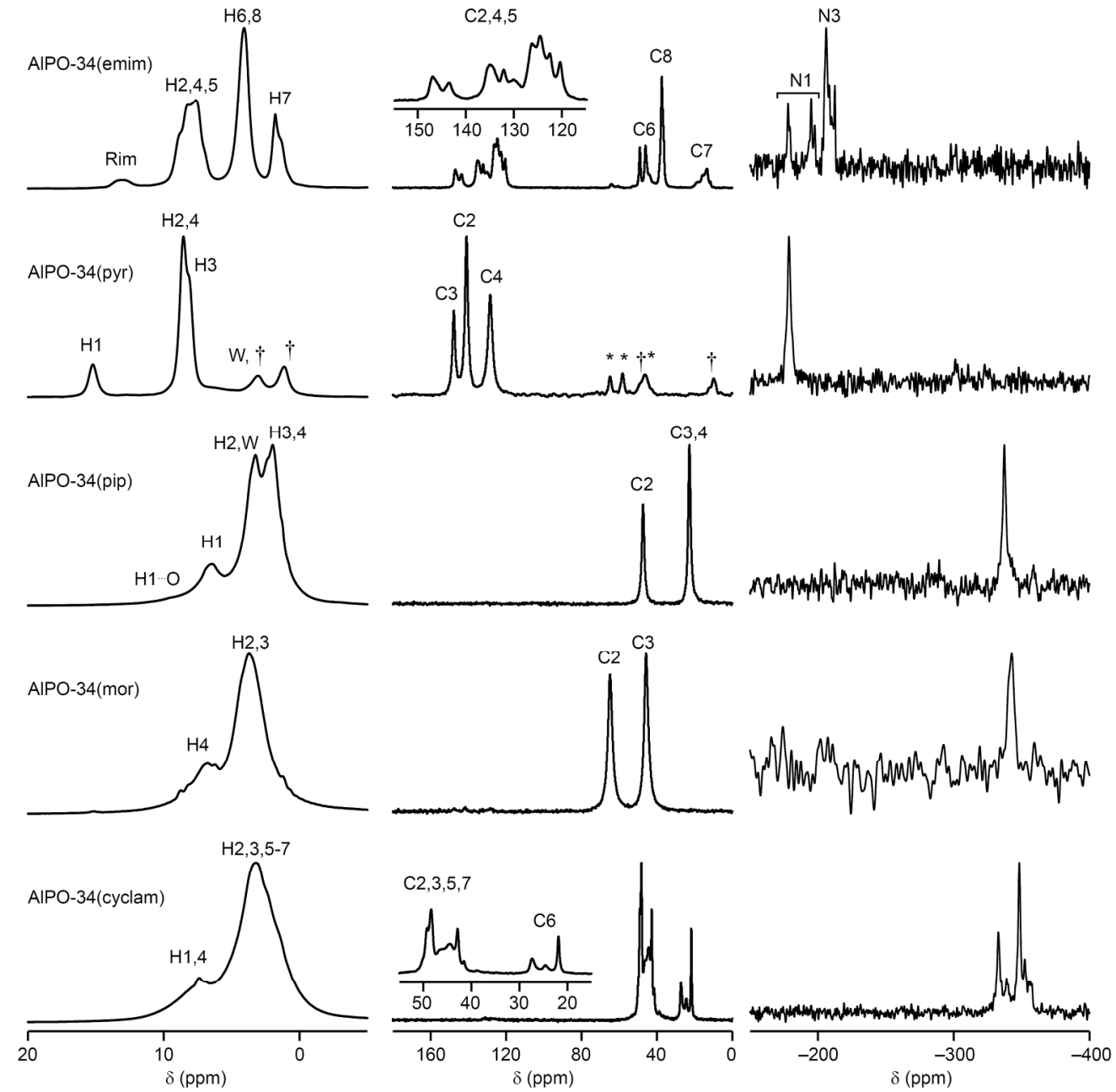

$205 \times 247 \mathrm{~mm}(300 \times 300$ DPI $)$ 

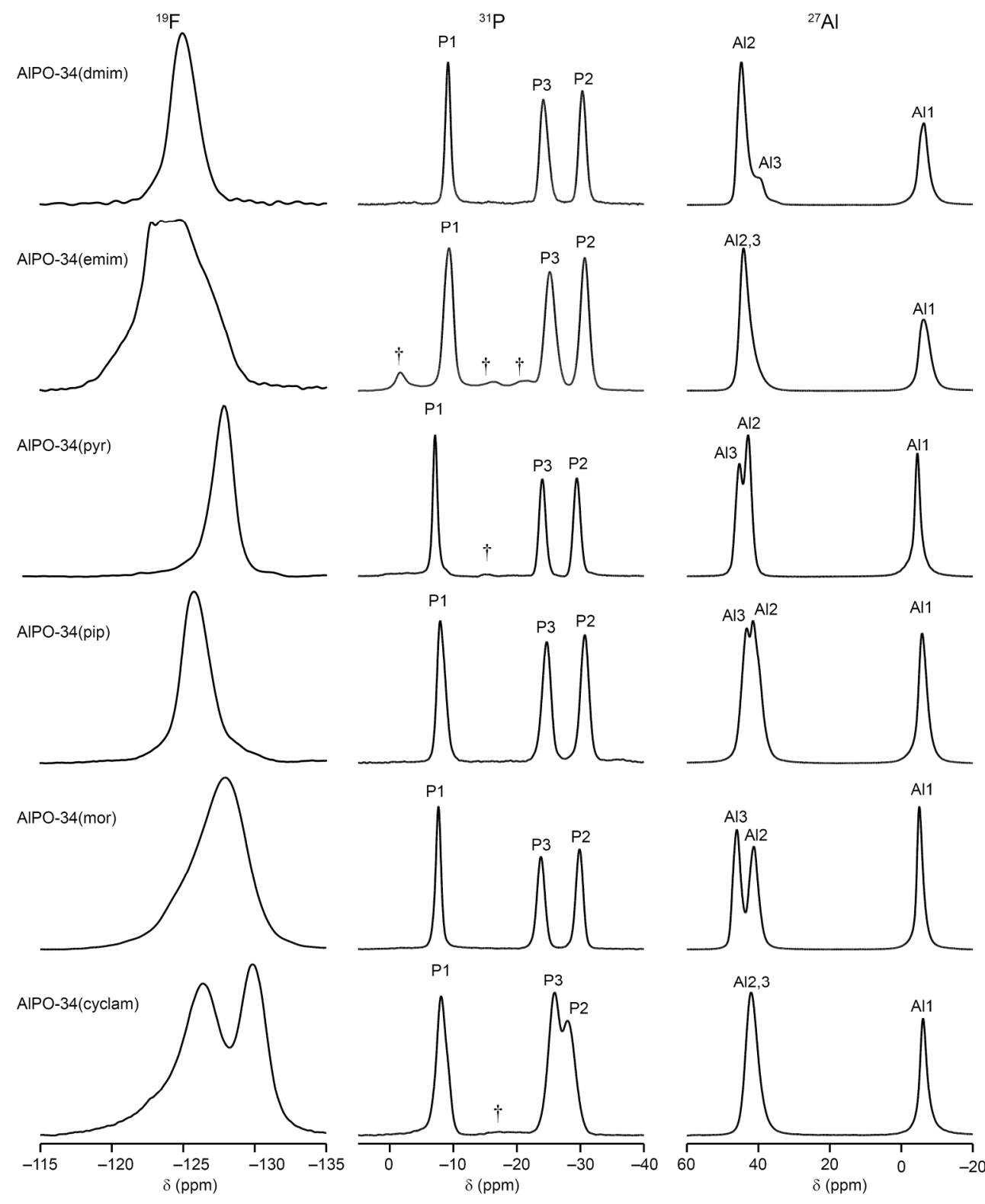
a

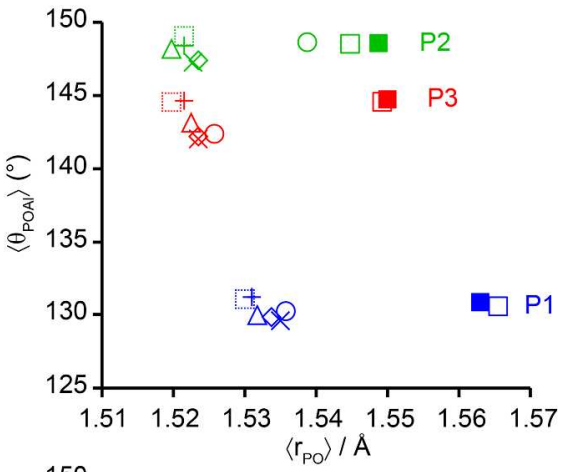

b

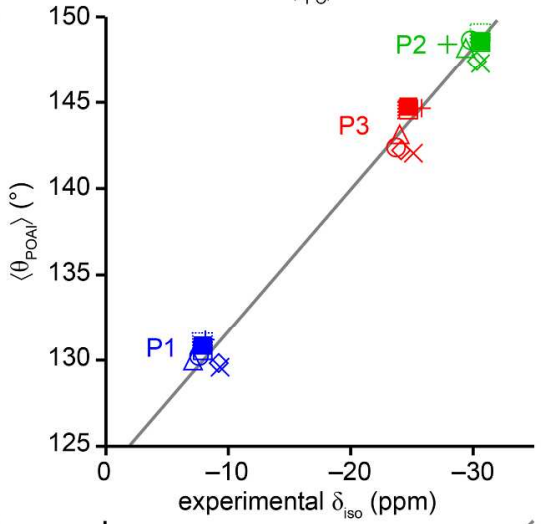

C

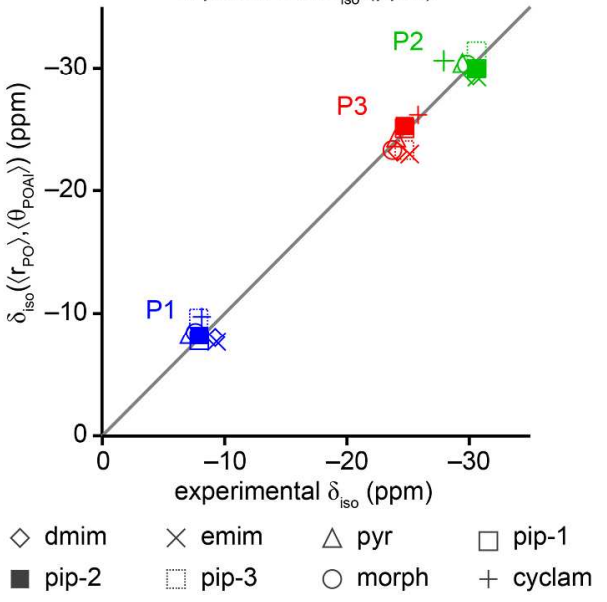

$172 \times 436 \mathrm{~mm}(300 \times 300$ DPI $)$ 

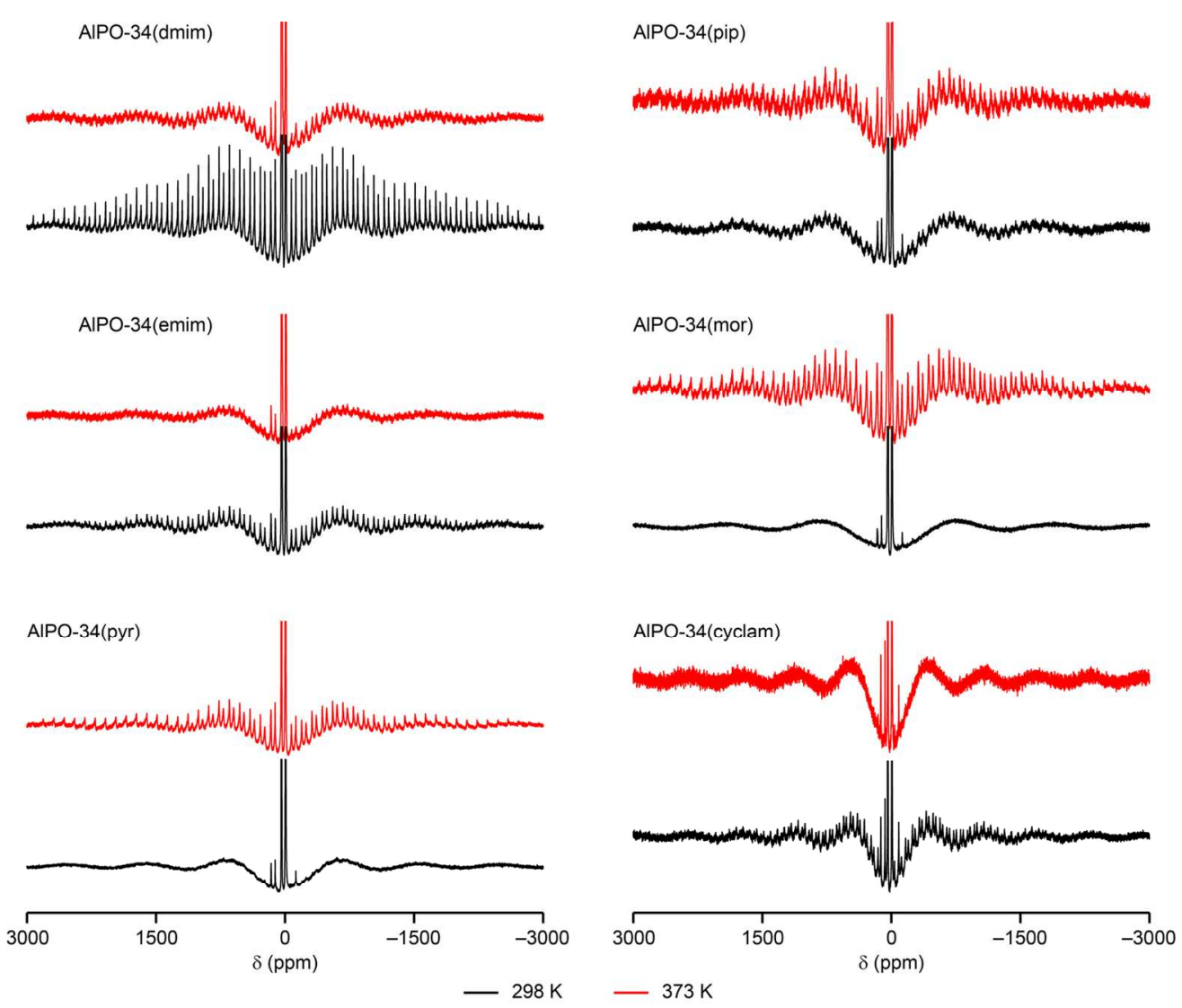

$142 \times 120 \mathrm{~mm}(300 \times 300$ DPI $)$ 

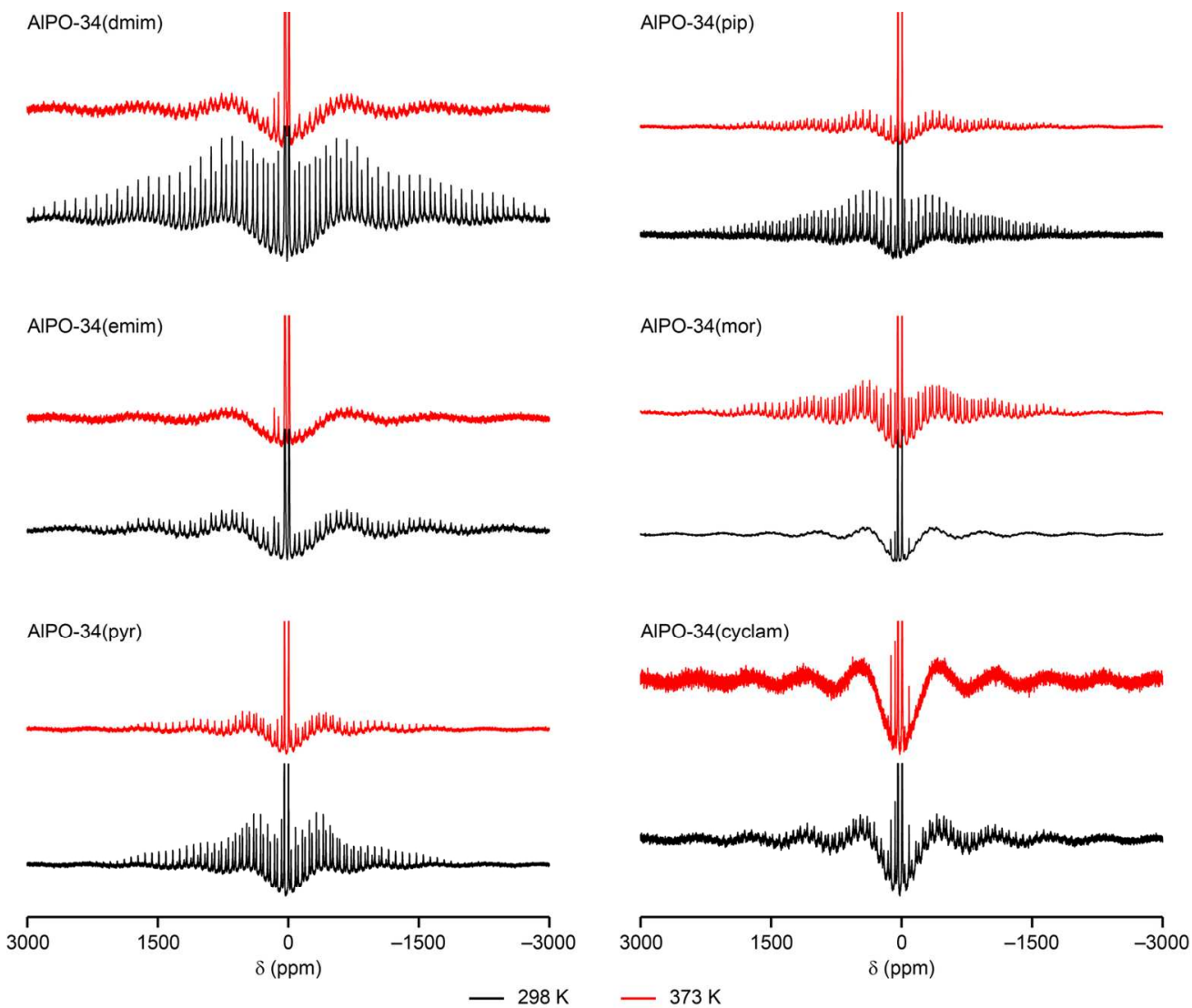

$143 \times 120 \mathrm{~mm}(300 \times 300 \mathrm{DPI})$ 


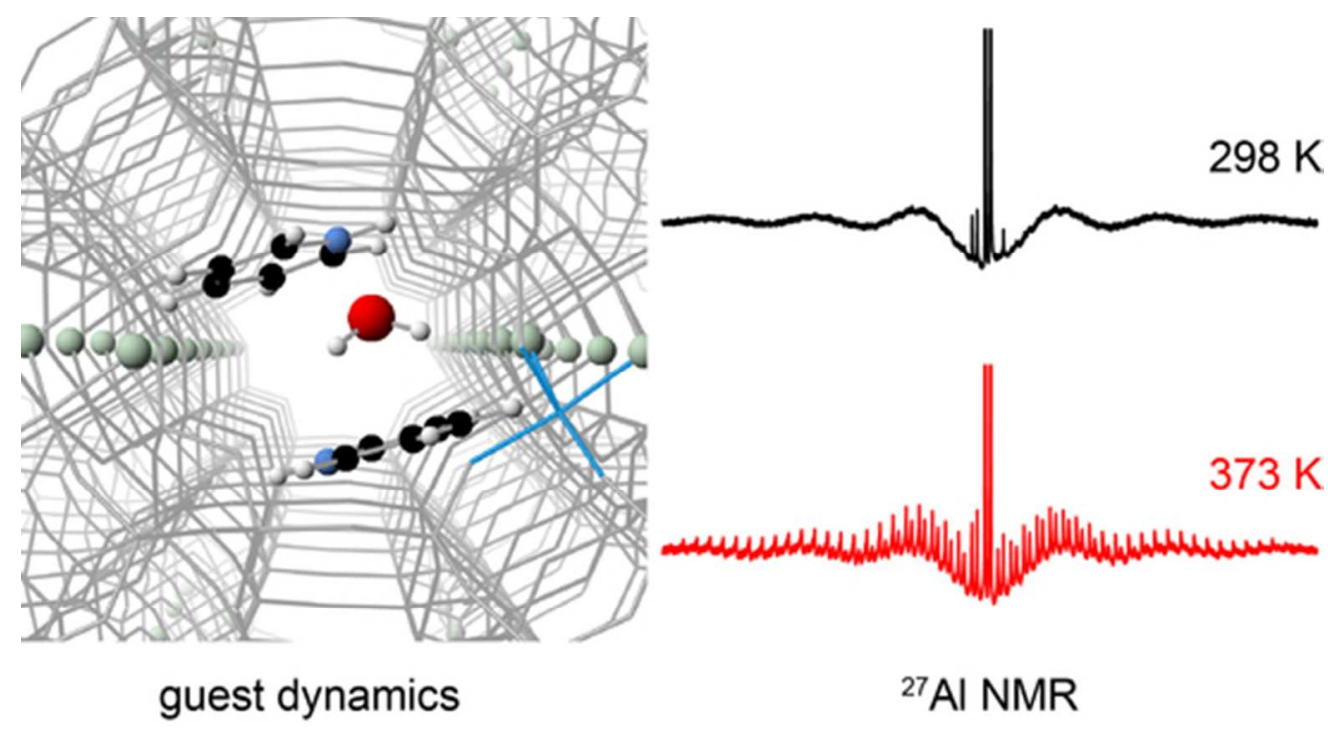

Table of contents graphic $46 \times 25 \mathrm{~mm}(300 \times 300$ DPI $)$ 